\title{
Response latencies of neurons in visual areas MT and MST of monkeys with striate cortex lesions
}

\author{
Paul Azzopardi ${ }^{\mathrm{a}, *}$, Mazyar Fallah ${ }^{\mathrm{a}, 1}$, Charles G. Gross ${ }^{\mathrm{a}}$, Hillary R. Rodman ${ }^{\mathrm{b}}$ \\ a Department of Psychology, Princeton University, Princeton, NJ 08544-1010, USA \\ ${ }^{\mathrm{b}}$ Department of Psychology and Yerkes Regional Primate Center, Emory University, Atlanta, GA, USA
}

Received 4 June 2003; accepted 20 June 2003

\begin{abstract}
Cortical area, MT (middle temporal area) is specialized for the visual analysis of stimulus motion in the brain. It has been suggested [Brain 118 (1995) 1375] that motion signals reach area MT via two dissociable routes, namely a 'direct' route which bypasses primary visual cortex (area, striate cortex (V1)) and is specialized for processing 'fast' motion (defined as faster than 6 \% $/ \mathrm{s}$ ) with a relatively short latency, and an 'indirect' route via area V1 for processing 'slow' motion (slower than $6 \%$ s) with a relatively long latency. We tested this proposal by measuring the effects of unilateral V1 lesions on the magnitudes and latencies of responses to fast- and slow-motion (depicted by random dot kinematograms (RDK) ) of single neurons in areas MT and medial superior temporal area (MST) of anaesthetized macaque monkeys. In the unlesioned hemisphere contralateral to a V1 lesion, response magnitudes and latencies of MT neurons were similar to those previously reported from MT neurons in normal monkeys, and there was no significant association between slow movement and long response latency $(>100 \mathrm{~ms})$, or between fast movement and short latency $(\leq 100 \mathrm{~ms})$. V1 lesions led to diminished response magnitudes and increased latencies in area MT of the lesioned hemisphere, but did not selectively abolish MT responses to slow moving stimuli, or abolish long-latency responses to either slow- or fast-moving stimuli. Response magnitudes and latencies in area MST, which receives visual inputs directly from area MT and is also specialized for visual analysis of motion, were unaffected by V1 lesions (though we have shown elsewhere that directionally-selective responses in both areas were impaired by V1 lesions). Overall, the results are incompatible with the hypothesis that there are dissociable routes to MT specialized for processing separately fast and slow motion.

(C) 2003 Published by Elsevier Ltd.
\end{abstract}

Keywords: Blindsight; Motion perception; Visual cortex; Sub-cortical pathways; V1; V5; Superior colliculus

\section{Introduction}

MT and MST are closely associated visual areas of the cerebral cortex specialized for processing motion. In monkeys, $90 \%$ of neurons in MT are sensitive to the direction of motion of a stimulus (Albright, 1984; Maunsell \& van Essen, 1983a,b; Zeki, 1974) and its destruction impairs visual direction discrimination (Newsome \& Pare, 1988; Newsome, Wurtz, \& Dürsteler, 1985; Pasternak \& Merigan, 1994). Its role in the visual perception of motion is under-

\footnotetext{
Abbreviations: EEG, electroencephalography; dLGN, dorsal lateral geniculate nucleus; MEG, magnetoencephalography; RDK, random dot kinematogram; V1, striate cortex; MT, middle temporal area; MST, medial superior temporal area

* Corresponding author. Present address: Department of Experimental Psychology, University of Oxford, South Parks Road, Oxford OX1 3UD, UK. Tel.: +44-1865-271415; fax: +44-1865-310447.

E-mail address: paul.azzopardi@psy.ox.ac.uk (P. Azzopardi).

${ }^{1}$ Present address: The Salk Institute, 10010 N. Torrey Pines Rd., La Jolla, CA 92037, USA.
}

lined by the fact that response rates of directionally-selective neurons co-vary with monkeys' decisions during direction discrimination (Britten, Shadlen, Newsome, \& Movshon, 1992; Newsome, Britten, \& Movshon, 1989), and stimulation of such neurons can influence the outcome of decisions during direction discrimination tasks (Salzman, Britten, \& Newsome, 1990; Salzman, Murasugi, Britten, \& Newsome, 1992).

The human brain contains an area homologous to MT, sometimes called MT+, bilateral damage of which can cause impairments of motion perception (Baker, Hess, \& Zihl, 1991; Hess, Baker, \& Zihl, 1989; Rizzo, Nawrot, \& Zihl, 1995; Vaina, Cowey, Eskew, LeMay, \& Kemper, 2001; Zihl, von Cramon, \& Mai, 1983). In the intact human brain, activation of MT+ assessed with PET and fMRI is correlated with the presentation of moving stimuli viewed passively or during motion discrimination (Tootell et al., 1995; Watson et al., 1993; Zeki et al., 1991); and consistent with these data, transcranial magnetic stimulation of $\mathrm{MT}+$ can cause transient impairments of motion percep- 
tion (Beckers \& Homberg, 1992; Hotson \& Anand, 1999; Hotson, Braun, \& Herzberg, 1994) or produce illusory moving phosphenes (Stewart, Battelli, Walsh, \& Cowey, 1999). Area MT receives the majority of its cortical inputs from areas V1 (primary visual cortex, also known as striate cortex) and V2, and projects directly to numerous cortical and sub-cortical destinations, including the adjacent cortical area MST (Maunsell \& van Essen, 1983a,b; Ungerleider \& Desimone, 1986), which is specialized for the perception of motion-in-depth (Britten \& van Wesel, 1998; Celebrini \& Newsome, 1994; Celebrini \& Newstome, 1995; Duffy \& Wurtz, 1991a,b; Graziano, Andersen, \& Snowden, 1994; Lagae, Maes, Raiguel, Xiao, \& Orban, 1994; Orban et al., 1992; Saito et al., 1986; Tanaka \& Saito, 1989).

It has been suggested that area MT receives visual inputs via two pathways, namely a 'direct' route from the retina to MT that bypasses area V1 via sub-cortical nuclei, and is specialized for processing fast motion (defined as faster than $6 \%$ ) with a relatively short latency, and an 'indirect' cortical route via area V1, specialized for processing slow motion (slower than $6 \%$ s) with a relatively long latency (ffytche, Guy, \& Zeki, 1995; Zeki, 1998). This model of the functional architecture of motion perception was dubbed 'dynamic parallelism' by its originators, because motion signals were conceived of as being routed via one of two parallel routes according to speed. It accounts for the existence of a double dissociation in which one patient with damaged V1 is able to detect and discriminate the direction of stimuli moved in the scotoma at speeds greater than about $6 \%$, but is unable to do so at lower speeds (Barbur, Watson, Frackowiak, \& Zeki, 1993), whereas another patient with bilateral lesions of MT+ can detect and discriminate the direction of speeds below $6 \%$ but not at higher speeds (Hess et al., 1989; Zihl et al., 1983). It is further supported by electrophysiological evidence from monkeys (Raiguel, Lagae, Gulyas, \& Orban, 1989) and from both normal and brain-damaged people (Beckers \& Zeki, 1985; ffytche, Guy, \& Zeki, 1995; ffytche, Guy, \& Zeki, 1996) that signals associated with fast-moving stimuli reach extrastriate cortex (presumably, area MT+) sooner than signals associated with slow-moving ones. Some of this evidence is controversial, because a number of studies have drawn different conclusions about the timing of signals reaching extrastriate cortex (Anderson, Holliday, Singh, \& Harding, 1996; Choi, Anand, \& Hotson, 1995; Holliday, Anderson, \& Harding, 1997) and because anatomical evidence suggests that the possible routes from the retina to MT via the superior colliculus, which could mediate responses to moving stimuli in the absence of V1 (Gross, 1991; Rodman, Gross, \& Albright, 1989, 1990), are potentially no more 'direct' than the route to MT via the lateral geniculate nucleus and the striate cortex (Johnson, 1999). A straightforward and decisive way to test the model is to measure the effects of striate cortex lesions in monkeys on the responses of neurons in ipsilateral area MT, for the selective interruption of the postulated 'slow' route to MT should lead to the abolition of all responses to motion at speeds of less than about $6 \%$, and to the abolition of all responses with longer latencies. Here, we report in full the results of such a test, which do not support these predictions (Azzopardi, Fallah, Regenbogen, Gross, \& Rodman, 1999), suggesting that the model proposed by ffytche et al. (1995) does not accurately depict the functional architecture of motion processing in the primate brain.

\section{Methods}

Visual responses of single neurons in areas MT and MST were recorded under anaesthesia from the impaired hemispheres of four macaque monkeys (Macaca fascicularis) with long-standing (6-8 years), unilateral ablations of area V1 sustained in adulthood (weighing 3.0-7.0 kg at the time of recording), and from the intact hemisphere of a single monkey with a similar lesion sustained in infancy (5 weeks of age) which served as a control (monkey FN, weighing $3.4 \mathrm{~kg}$ ). The procedures were approved by the Princeton University Institutional Animal Care and Use Committee, and carried out in accordance with the N.I.H. Guidelines for Care and Use of Laboratory Animals (1985).

\subsection{Striate cortex lesions}

The cortical lesions were made by sub-pial aspiration under aseptic surgical conditions, as previously described (Rodman et al., 1989). In one case (monkey DR) the lesion was restricted to the occipital operculum, representing the central $10^{\circ}$ of vision, approximately; in two cases (DJ and SC) the lesions extended beyond the operculum to the medial surface of the occipital pole and the lip of the calcarine sulcus, representing central vision to an eccentricity of $15-60^{\circ}$; and in one case (RY) the lesion was virtually complete, extending along the fundus of the calcarine sulcus, representing virtually the entire visual hemifield to an eccentricity of at least $60^{\circ}$. The behavioural responses of these monkeys to stimuli presented in their impaired visual fields were tested extensively over a period of years before electrophysiological recordings were carried out, and the results have been described elsewhere (Gross, Moore, \& Rodman, 2003; Moore, Rodman, Repp, \& Gross, 1995, 1996, 2001).

\subsection{Preparation for recording}

The responses of single neurons to visual stimulation were measured during repeated recordings under anaesthesia as previously described (Rodman \& Albright, 1989; Rodman et al., 1989). At least 1 week before the first recording session, and immediately following pre-medication with atropine sulphate $(0.08 \mathrm{mg} / \mathrm{kg}$ i.m. $)$, a $2.5 \mathrm{~cm}$ diameter stainless steel well and cap, together with a stereotaxically-positioned headbolt, were fixed to the skull with titanium screws and dental acrylic under aseptic conditions and ketamine/acepromazine anaesthesia (ketamine 
hydrochloride: initial dose, $30 \mathrm{mg} / \mathrm{kg}$ i.m.; acepromazine, $0.40 \mathrm{mg} / \mathrm{kg}$ i.m., supplemented as needed). A daily injection of antibiotic (Baytril, $2.5 \mathrm{mg} / \mathrm{kg}$ i.m.) and a twice-daily injection of analgaesic (buprenorphine, $0.01 \mathrm{mg} / \mathrm{kg}$ i.m.) was administered for several days afterwards to prevent infection and facilitate recovery.

On the day of a recording session, the animal was given atropine (i.m., as above) and a restraining dose of ketamine/acepromazine (ketamine hydrochloride, $10 \mathrm{mg} / \mathrm{kg}$; acepromazine, $0.4 \mathrm{mg} / \mathrm{kg}$ i.m.), before being anaesthetized with $2 \%$ halothane in a 7:3 mixture of nitrous oxide and oxygen. It was then intubated and placed on a bed with its head held stereotaxically by means of the implanted bolt. The cap was removed from the well and, if necessary (such as on the first recording session, or a significant change in recording site), a small craniotomy was performed in which the dura was left intact. A microdrive holding an insulated microelectrode, protected by a stainless steel guard-tube (an 18-gauge hypodermic needle), was mounted stereotaxically on the apparatus, and the guard-tube advanced until it just penetrated the dura. Halothane was then discontinued, and anaesthesia maintained by a mixture of $7: 3$ nitrous oxide and oxygen. Eye movements were prevented with an intravenous infusion of pancuronium bromide (Pavulon, Organon NV; $0.03 \mathrm{mg} /(\mathrm{kgh})$ ) in dextrose-lactated Ringer's solution, whilst the animal was maintained on a ventilator. End-tidal $\mathrm{CO}_{2}$ levels were monitored with a capnograph, and the respiration rate was adjusted within the range of 18-26 breaths/min to maintain a concentration of about $4 \%$. Heart and body temperature were also monitored, and electrically-heated blankets were used to maintain core temperature within $37-38^{\circ} \mathrm{C}$. The pupils of the eyes were dilated with cyclopentolate (1\%), and the corneas covered with contact lenses selected to focus the eyes on a rear-projection tangent screen $57 \mathrm{~cm}$ distant. The position of the fovea and the optic disc was plotted for each eye by means of a reversible ophthalmoscope, and checked for drift at regular intervals throughout the session, which lasted between 12 and $17 \mathrm{~h}$. Towards the end of a session, the Pavulon infusion was discontinued and reversal of paralysis was facilitated with an intravenous dose of neostigmine $(0.05 \mathrm{mg} / \mathrm{kg}$ i.v. $)$, preceded by atropine $(0.025 \mathrm{mg} / \mathrm{kg}$ i.v.). The recording well was resealed, and the animal transferred to a recovery cage for observation once it was breathing normally. Recording sessions were separated by a minimum of 5 days.

\subsection{Recording procedure and visual stimulation}

Neural responses (extracellular potentials, or 'spikes') were recorded using varnish-coated electrodes with tips of c. $10 \mu \mathrm{m}$ and an impedance of $0.5-5 \mathrm{M} \Omega$. The electrodes were tilted roughly $40^{\circ}$ anterior to posterior in the parasagittal plane, so as to penetrate the upper and lower banks of the superior temporal sulcus normal to the surface of the cortex. Extracellular potentials were amplified, filtered, and displayed on an oscilloscope, and potentials from single neurons were isolated with a windowed spike trigger (Bak Instruments) before being converted to TTL pulses and stored in real-time via a fast digital acquisition board installed in an IBM-PC microcomputer running custom software. Both the background responses and the window-thresholded spikes were relayed to a small loudspeaker for audio-monitoring.

Isolated neurons were first characterized by means of informal tests employing moving bars and spots generated on a back-projection screen by mean of a hand-held projector, and using objects such as wooden rods and black card covered with random arrays of white dots manipulated in the visual field. Although many neurons were clearly responsive to these stimuli, it was sometimes difficult to plot the receptive fields of neurons in the lesioned hemisphere, where responses tend to be weaker and more variable than normal (as previously reported by Rodman et al., 1989). All isolated units were also screened using a small set of computer-generated stimuli presented on a video display (see below), which consisted of six presentations each of random dot kinematograms (RDKs) depicting translation in four directions at two speeds, 4 and $20 \%$ s (selected so as to straddle the cutoff between 'slow' and 'fast' of $6 \%$ s specified by ffytche et al., 1995, and similar to the speeds used in that study), plus a blank screen and a stationary pattern of dots, presented in pseudo-random order, and the associated spike rates were analyzed objectively on-line for responsiveness to movement using ANOVA. If possible, the stimuli were centred on the plotted receptive field, otherwise they were presented in standard positions selected so that the stimulus would be encompassed by the intended field defect.

Neurons which responded significantly to the presence of visual stimuli, determined as described above, were then subjected to a further series of tests with computer-generated stimuli. These were high-contrast RDKs which depicted translation and motion-in-depth (expansion and contraction), generated using custom software on an IBM PC compatible computer and a standard SVGA video card. The images were displayed on a $14 \mathrm{in}$. video display at a non-interlaced frame rate of $70 \mathrm{~Hz}$. Some of the RDKs depicting translation were generated with a VSG2/4 Visual Stimulus Generator (Cambridge Research Systems, UK), using custom software.

The RDKs depicting translation consisted of images of $0.5^{\circ}$ diameter white dots (luminance $30 \mathrm{~cd} / \mathrm{m}^{2}$ ) on a dark background (luminance $0.03 \mathrm{~cd} / \mathrm{m}^{2}$ ) placed at random positions on the screen at an average density of $0.142 \mathrm{dots} / \mathrm{deg}^{2}$, and viewed through circular windows of diameter between 5 and $20^{\circ}$. The dots moved with $100 \%$ coherence and 'infinite' lifetime, and depicted motion in $4\left(0,90,180\right.$, and $\left.270^{\circ}\right)$ or $8\left(0,45,90,135,180,225,270\right.$, and $\left.315^{\circ}\right)$ directions at two speeds (4 and $20 \%$ ).

RDKs depicting motion-in-depth were implemented according to an algorithm described by Graziano et al. (1994), in which dots with limited lifetime are displaced in a radial direction by the distance $k \times r$, where $k$ is a constant and $r$ is the radial distance between their current location and the 
focus of expansion or contraction, and in the present experiments, values of $k$ were chosen to yield speeds of 4 and $20 \%$ at a radius of $10^{\circ}$ from that point. Dot diameter was $0.25^{\circ}$ and dot density $0.414 \mathrm{dots} / \mathrm{deg}^{2}$.

Responses to stimuli depicting translation or motion-indepth were measured in separate blocks of trials during monocular stimulation via the eye which initially yielded the strongest response. The stimuli were presented in randomized order together with a static pattern of dots and a blank image. The stimulus duration was $1000 \mathrm{~ms}$, the inter-stimulus interval was $5 \mathrm{~s}$, and typically there were between 5 and 10 presentations per condition.

The responses (spikes per second calculated over a $1000 \mathrm{~ms}$ period) were analyzed using one-way ANOVA to determine whether or not the unit responded to the presentation of a stimulus, and two-way ANOVA to determine
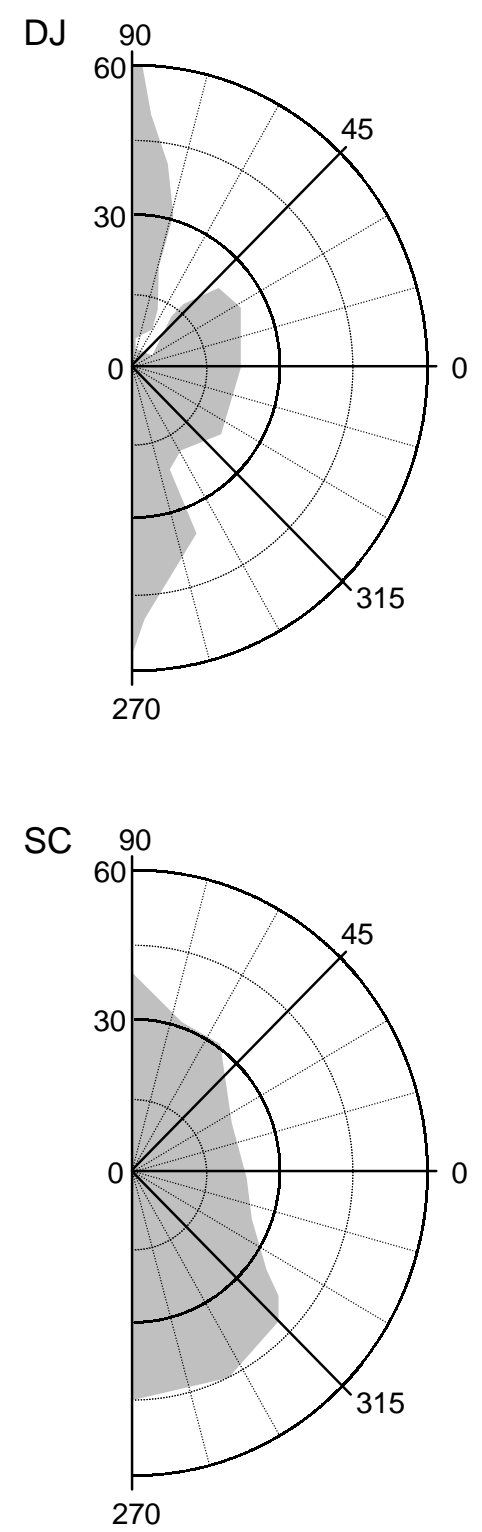

whether units responded selectively to stimulus speed and/or direction. For those neurons which responded significantly to the presentation of a stimulus, response latencies were measured from peristimulus-time histograms (smoothed using a Gaussian filter with a standard deviation of $5 \mathrm{~ms}$ ) as the time taken for the response to the most effective stimulus (i.e. the best direction of movement) to deviate from the mean spontaneous rate by more than 2.33 Poisson standard deviations (estimated from the unfiltered histograms from the moment the stimulus was presented). The choice of threshold and the amount of smoothing was not critical.

\subsection{Histology}

At the end of the experiments, the animals were given a lethal dose of sodium pentobarbitol and perfused
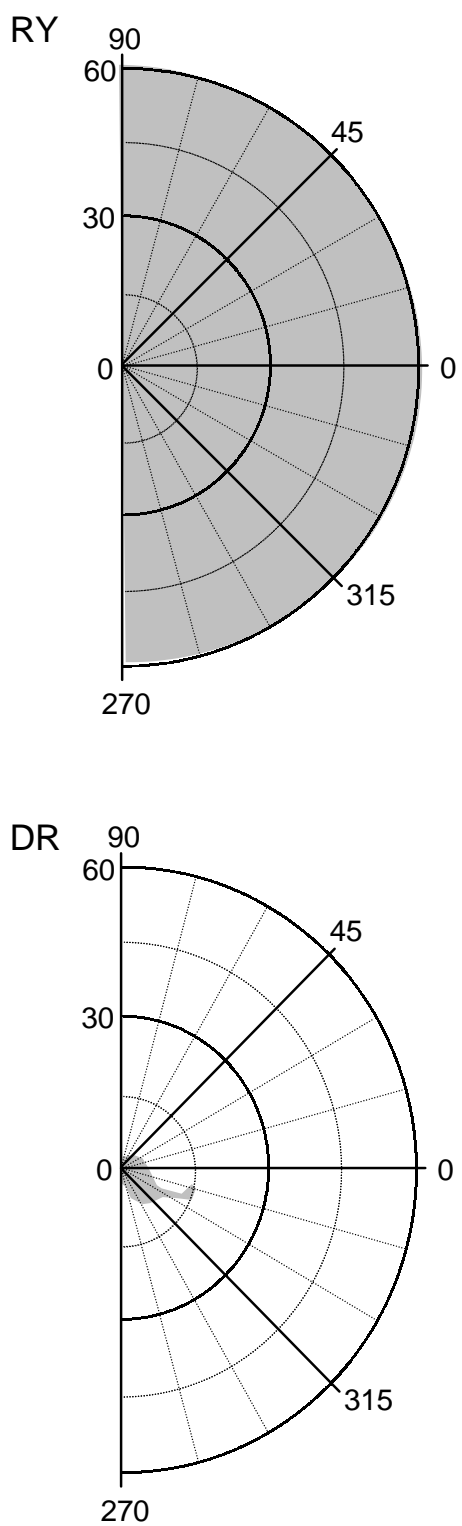

Fig. 1. Visual field defects corresponding to striate cortex lesions in four macaque monkeys, reconstructed on the basis of cortical damage and retrograde degeneration in the lateral geniculate nucleus. 
transcardially with 11 of saline + heparin, followed by $212.5 \%$ paraformaldehyde. The brains were removed, stored successively in 5, 10 and 15 sucrose in $2.5 \%$ paraformaldeyhe until they sank; they were blocked stereotaxically, and then sectioned in the parasagittal plane on a freezing microtome at $50 \mu \mathrm{m}$ thickness. A one in six series of sections was stained with cresyl violet, and another with Gallyas' silver stain method for myelin (Gallyas, 1969), and mounted on glass slides.
Recording sites were identified from electrode tracks in the histological sections, combined with stereotaxic information, notes on recording transitions and the position of micro-lesions made during some electrode penetrations, and assigned to visual areas by identifying architectonic boundaries in sections stained for myelin. The field defects corresponding to the lesions were reconstructed on the basis of cortical damage and retrograde degeneration in the dorsal lateral geniculate nucleus (dLGN), in conjunction

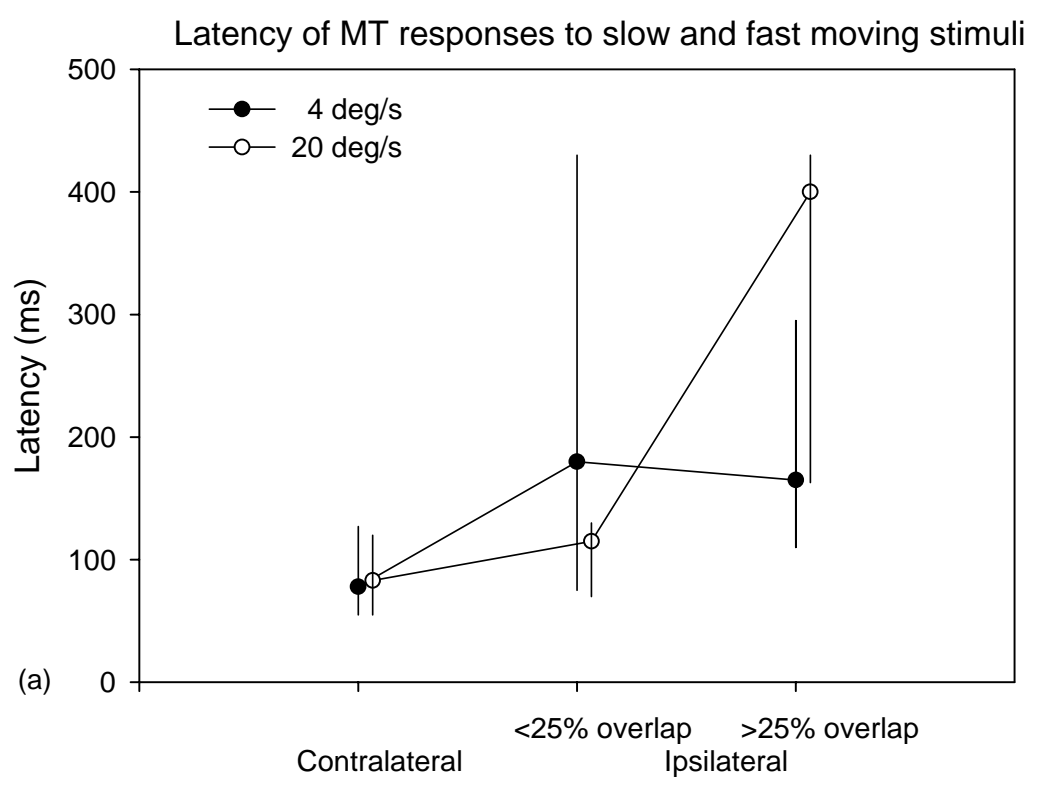

Position of stimulus relative to field defect

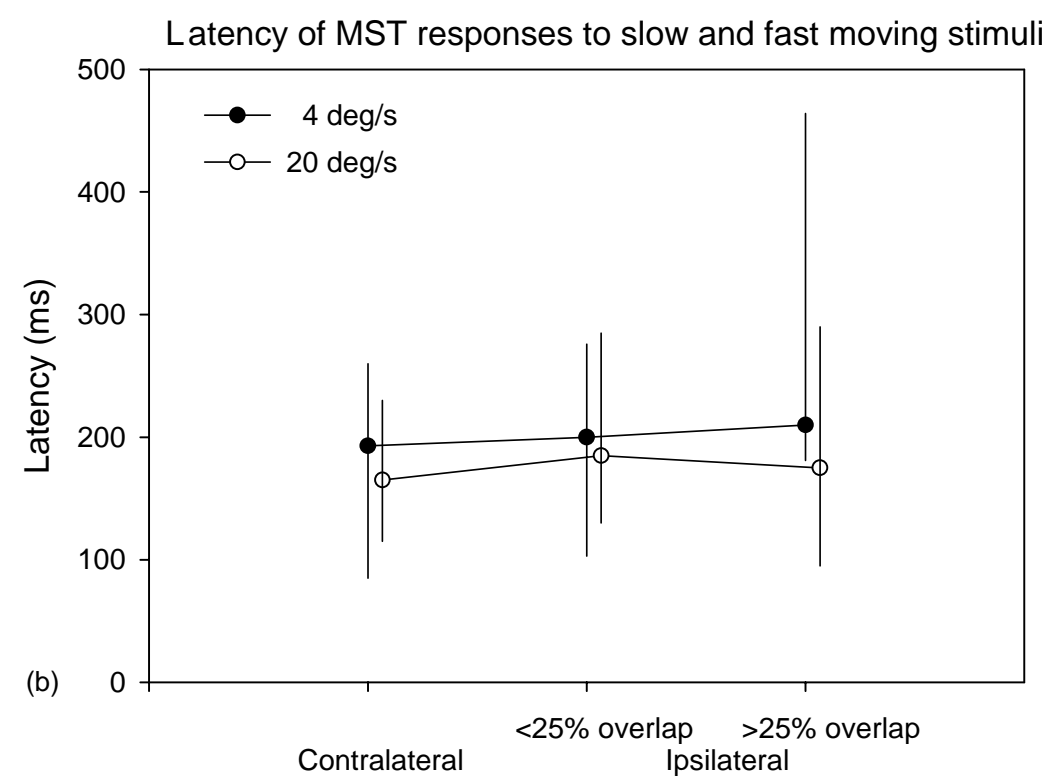

Position of stimulus relative to field defect

Fig. 2. Median response latencies to slow and fast moving stimuli in areas MT and MST in the presence and absence of striate cortex lesions. Bars indicate interquartile ranges. 
with published maps of striate cortex (van Essen, Newsome, \& Maunsell, 1984) and dLGN (Malpeli \& Baker, 1975; Malpeli, Lee, \& Baker, 1996). The field defects plotted in Fig. 1 represent the envelope of the two kinds of estimate.

\section{Results}

Neurons driven by visual stimulation inside the field defect were difficult to isolate, and so the number of such neurons sampled was relatively small. Responses obtained from the lesioned hemisphere were therefore classified according to whether the stimulus had been presented mainly outside the scotoma ( $25 \%$ or less of overlap with the scotoma) or mainly inside the scotoma (more than $25 \%$ overlap), with these particular cut-offs chosen to ensure sufficient numbers of neurons in each category to permit statistical analysis of the resultant contingency tables. In total, we recorded from 46 visually-responsive MT neurons, 22 in the unlesioned hemisphere, and 24 in the lesioned hemispheres, of which 12 were classified as mainly outside, and 12 mainly inside the scotoma; and a total of 58 visually-responsive MST neurons, 19 in the unlesioned hemisphere, and 39 in the lesioned hemispheres, of which 32 were mainly outside and 7 were mainly inside the scotoma. The sample includes a number of neurons for which it was not possible to plot receptive fields (7/12 MT and 5/32 MST neurons classified as mainly outside, and 4/7 MST neurons classified as mainly inside the scotoma).

\subsection{Response latencies}

The average response latencies recorded from MT and MST neurons in response to the most effective stimulus at slow $\left(4 \%\right.$ s) and fast $\left(20^{\circ} / \mathrm{s}\right)$ speeds are presented in Table 1 and Fig. 2.

In the unlesioned hemisphere (monkey FN, contralateral to a V1 lesion), median response latencies of MT neurons
Table 1

Response latencies of MT and MST neurons recorded from macaque monkeys with striate cortex lesions

\begin{tabular}{lccll}
\hline Area & $\begin{array}{l}\text { Stimulus } \\
\text { speed } \\
(\%)\end{array}$ & \multicolumn{3}{l}{ Position of stimulus relative to field defect } \\
\cline { 3 - 5 } & Contralateral & $\begin{array}{l}\text { Ipsilateral } \\
(<25 \% \text { in } \\
\text { scotoma })\end{array}$ & $\begin{array}{l}\text { Ipsilateral } \\
(>25 \% \text { in } \\
\text { scotoma })\end{array}$ \\
\hline MT & 4 & $78(55-119)$ & $180(98-365)$ & $165(115-265)$ \\
& 20 & $83(55-119)$ & $115(75-130)$ & $400(170-425)$ \\
MST & 4 & $193(85-255)$ & $200(105-270)$ & $210(185-460)$ \\
& 20 & $165(116-228)$ & $185(133-278)$ & $175(95-260)$
\end{tabular}

Key: Data are medians and (interquartile ranges) of latencies, in milliseconds.

to stimuli moving at 4 and $20 \%$ s were $78 \mathrm{~ms}$ (interquartile range 55-119) and $83 \mathrm{~ms}$ (interquartile range 55-119), respectively. These values are virtually identical to those recorded from MT neurons in intact macaque monkeys by Raiguel, Xiao, Marcar, \& Orban (1999) using similar RDKs, and by Lagae et al. (1994) using similar RDKs at identical speeds (Table 2). Almost all responses commenced within $150 \mathrm{~ms}$, and the majority within $50-100 \mathrm{~ms}$. Latencies recorded from MT ipsilateral to striate cortex lesions were substantially longer, irrespective of the speed of the stimulus or its position relative to the field defect (Table 1), and varied significantly with stimulus position both at $4 \%$ (Kruskal-Wallis test, $\chi^{2}=7.91$, d.f. $=2, P<0.05$ ) and at $20 \%$ s (Kruskal-Wallis test, $\chi^{2}=16.01$, d.f. $=2, P<$ $0.001)$. Response latencies to moving stimuli were significantly longer in MT ipsilateral to a striate cortex lesion, by an average of between 30 and $320 \mathrm{~ms}$, depending on the speed and position of the stimulus. These are summarized in Fig. 2(a).

In MST contralateral to the lesion, the median latency was $193 \mathrm{~ms}$ (interquartile range 85-255) in response to stimuli moving at $4 \%$, and $165 \mathrm{~ms}$ (interquartile range 116-228) at $20 \%$ s. These values correspond very closely to those recorded by Lagae et al. (1994) in response to RDKs depicting expansion and contraction at the same speeds from MST

Table 2

Reference data: average responses latencies recorded previously from neurons in MT and MST of intact macaque monkeys under anaesthesia

\begin{tabular}{lccc}
\hline Stimulus & Response latency & & References \\
\cline { 2 - 3 } & Area MT & Area MST & Raiguel et al. (1989) \\
\hline Bars (slits) & $84(64-136)$ & - & Schmolesky et al. (1998) \\
$\begin{array}{l}\text { Flashing spot/bar } \\
\text { RDK-translation (\%) }\end{array}$ & $72 \pm 10.3$ & $74 \pm 16.1$ & Lagae et al. (1994) \\
4 & $80(60-120)$ & $110^{\mathrm{a}}(95-160)$ & Lagae et al. (1994) \\
20 & $75(55-95)^{\mathrm{a}}$ & $105(65-115)$ & Raiguel et al. (1999) \\
RDK-expansion/contraction ${ }^{\mathrm{b}}$ & $87 \pm 45$ & - & Lagae et al. (1994) \\
2 & $120(90-230)$ & $180(120-440)$ & Lagae et al. (1994) \\
10 & $80(80-115)$ & $190(135-275)$ &
\end{tabular}

Key: Data are given as mean \pm S.D., or median (interquartile range).

${ }^{a}$ Values interpolated from graphs.

${ }^{\mathrm{b}}$ Speeds given are radial speeds at mid-radius, corresponding to maximum speeds at edge of stimulus of 4 and $20^{\circ} /$ s, respectively. 
of unlesioned macaque monkeys (Table 2). The tendency for latencies to be slightly shorter in response to faster stimuli is in line with previous observations (Kawano, Shidara, Watanabe, \& Yamane, 1994; Lagae et al., 1994). MST response latencies recorded ipsilateral to V1 lesions were fairly similar to those recorded on the contralateral side (Table 1), and overall they did not vary significantly with stimulus position, either at $4 \% \mathrm{~s}$ (Kruskal-Wallis test, $\chi^{2}=1.438$, d.f. $=$ $2, P>0.05$ ) or at $20 \%$ (Kruskal-Wallis test, $\chi^{2}=0.187$, d.f. $=2, P>0.05)$. This is summarized in Fig. 2(b). Unlike MT, response latencies in MST were not affected by striate cortex lesions.

\subsection{Response magnitudes}

The strength of neural responses was quantified as the difference between the maximum and minimum response rates, a measure known as the differential response magnitude (Albright, 1984). This is not the only possible measure of neural response strength, but it has been adopted here so that the results can be compared directly with the results of previous studies. The average response magnitudes elicited from MT and MST neurons by the most effective stimulus at 4 and $20 \%$ are presented in Table 3 and Fig. 3.

In MT contralateral to the lesion, response magnitudes to both speeds of stimulus were distributed across the range $0-50$, which is comparable to the range of values found previously in MT of unlesioned macaque monkeys (Albright, 1984). The median response magnitude recorded in the presence of RDKs moving at $20 \%$ in the optimum direction

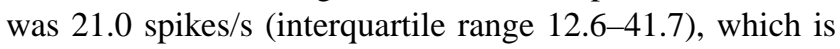
also similar to the mean value of 18.1 found previously in the absence of striate cortex lesions (Albright, 1984). There was no obvious tendency for responses in MT in the intact hemisphere to be associated exclusively with either slowor fast-moving stimuli, though the majority of neurons responded more vigorously to stimuli moving at $20 \%$ s than at $4 \%$ s (median 12.4, interquartile range 3.9-19.6). The difference is just significant (Mann-Whitney test, $U=157, \chi^{2}=$ 3.98 , d.f. $=1, P<0.05$.) This reflects the fact that almost every neuron sampled responded better to the faster stimulus, and it is consistent with previous findings that MT neurons

Table 3

Differential response magnitudes of MT and MST neurons in macaque monkeys with striate cortex lesions

\begin{tabular}{lclll}
\hline Area & $\begin{array}{l}\text { Stimulus } \\
\text { speed } \\
(\% / s)\end{array}$ & \multicolumn{3}{l}{ Position of stimulus relative to field defect } \\
\cline { 3 - 5 } & & Contralateral & $\begin{array}{l}\text { Ipsilateral } \\
(<25 \% \text { in } \\
\text { scotoma })\end{array}$ & $\begin{array}{l}\text { Ipsilateral } \\
(>25 \% \text { in } \\
\text { scotoma })\end{array}$ \\
\hline MT & 4 & $12.4(3.9-19.6)$ & $3.6(1.8-5.4)$ & $2.7(1.7-3.7)$ \\
& 20 & $21.0(12.6-41.7)$ & $5.9(1.8-9.1)$ & $1.9(1.7-3.3)$ \\
MST & 4 & $4.1(2.6-7.5)$ & $4.0(2.0-6.3)$ & $2.3(1.7-3.1)$ \\
& 20 & $4.7(2.9-12.6)$ & $6.8(3.5-13.4)$ & $3.4(1.5-5.3)$ \\
\hline
\end{tabular}

Key: Data are medians and (interquartile ranges) of response magnitudes. tend to be tuned to respond best to speeds of between 20 and $32^{\circ}$ /s (Rodman \& Albright, 1987). Ipsilateral to striate cortex lesions, responses of MT were much weaker, irrespective of the speed of the stimulus or whether or not the stimulus was positioned mainly inside, or mainly outside the field defect. It is worth noting that every neuron included in this sample responded significantly to visual stimulation (as determined by ANOVA), but on average neurons were only as responsive to moving stimuli as are MT neurons in unlesioned macaque monkeys to the presentation of a non-moving bar (mean response magnitude 5.8 spikes/s; Albright, 1984). The effect of stimulus position on response magnitude was highly significant, both at $4 \%$ s (Kruskal-Wallis test, $\chi^{2}=$ 17.69, d.f. $=2, P<0.001)$ and at $20 \%$ (Kruskal-Wallis test, $\chi^{2}=25.49$, d.f. $\left.=2, P<0.001\right)$. Thus, in these experiments, unilateral striate cortex lesions compromised the strengths of responses of neurons in ipsilateral area MT, but did not abolish them completely, just as reported previously (Girard, Salin, \& Bullier, 1992; Rodman et al., 1989).

Contralateral to the lesion, MST neurons (median 4.1 and 4.7 spikes/s at 4 and $20 \%$ s, respectively) were considerably less responsive than were both MT neurons on that side (median 12.4 and 21.0 spikes/s) and neurons in MST reported by Orban, Lagae, Raiguel, Xiao, \& Maes (1995) (median 18.0 spikes/s at the optimum speed). However, the latter values refer to net responses (i.e. the difference between the maximum response and the spontaneous rate) which is not necessarily the same as response magnitude as defined above, and any difference not attributable to that may be due to the fact and that Orban et al. used larger stimuli and a wider range of stimulus speeds. We are confident that the stimuli used in the present study were appropriate for MST neurons because they evoked directionally-selective and position-invariant responses to RDKs depicting motion-in-depth from neurons in the unlesioned hemisphere (Azzopardi, Fallah, Gross, \& Rodman, 1998), in line with previous studies of MST neurons (Duffy \& Wurtz, 1991a,b; Graziano et al., 1994; Lagae et al., 1994; Saito et al., 1986; Tanaka \& Saito, 1989). In the lesioned hemisphere, response magnitudes of MST neurons, whether mainly outside or mainly inside the field defect, were only slightly impaired, and the effect of position was not significant, either at $4 \%$ (Kruskal-Wallis test, $\chi^{2}=1.88$, d.f. $=2, P>0.05$ ), or at $20^{\circ} / \mathrm{s}$ (Kruskal-Wallis test, $\chi^{2}=3.04$, d.f. $=2, P>0.05$ ). Thus, unlike MT, striate cortex lesions did not significantly affect response magnitudes of MST neurons.

\subsection{Implications for dynamic parallelism}

According to ffytche's et al.'s model (ffytche et al., 1995), the long-latency responses of MT neurons to slow-moving stimuli, mediated by the geniculo-striate route to MT, should be abolished by striate cortex lesions, whereas the short-latency responses of MT neurons to fast-moving stimuli, mediated by sub-cortical nuclei, should not. The averages of response magnitudes and latencies presented above 
Magnitude of MT responses to slow and fast moving stimuli

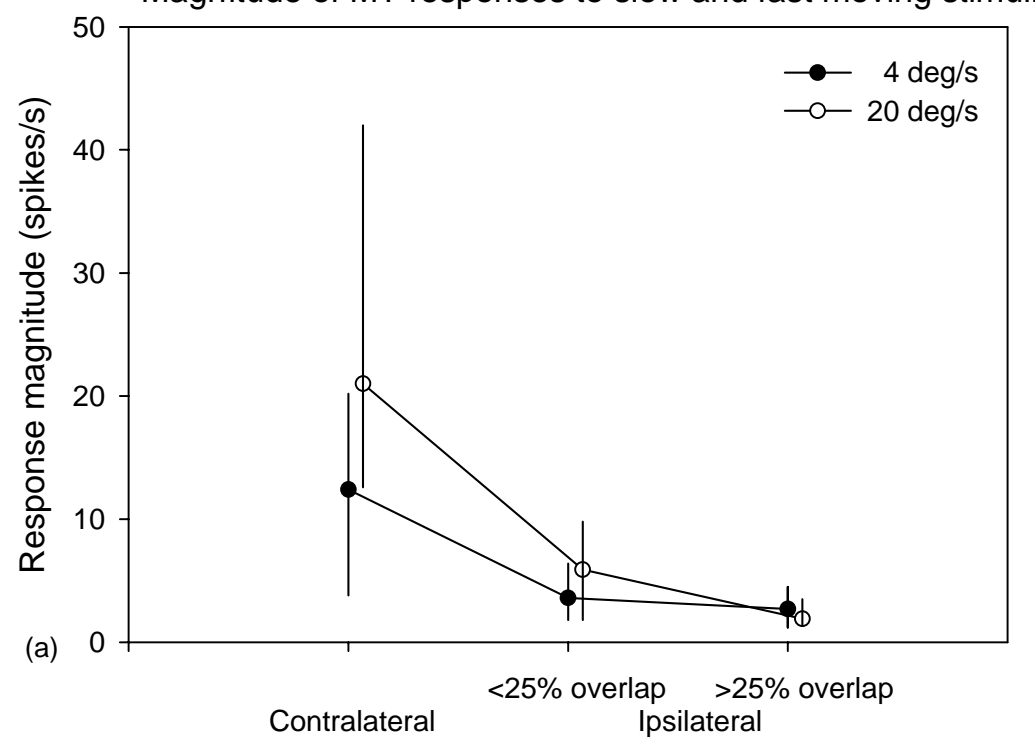

Position of stimulus relative to field defect

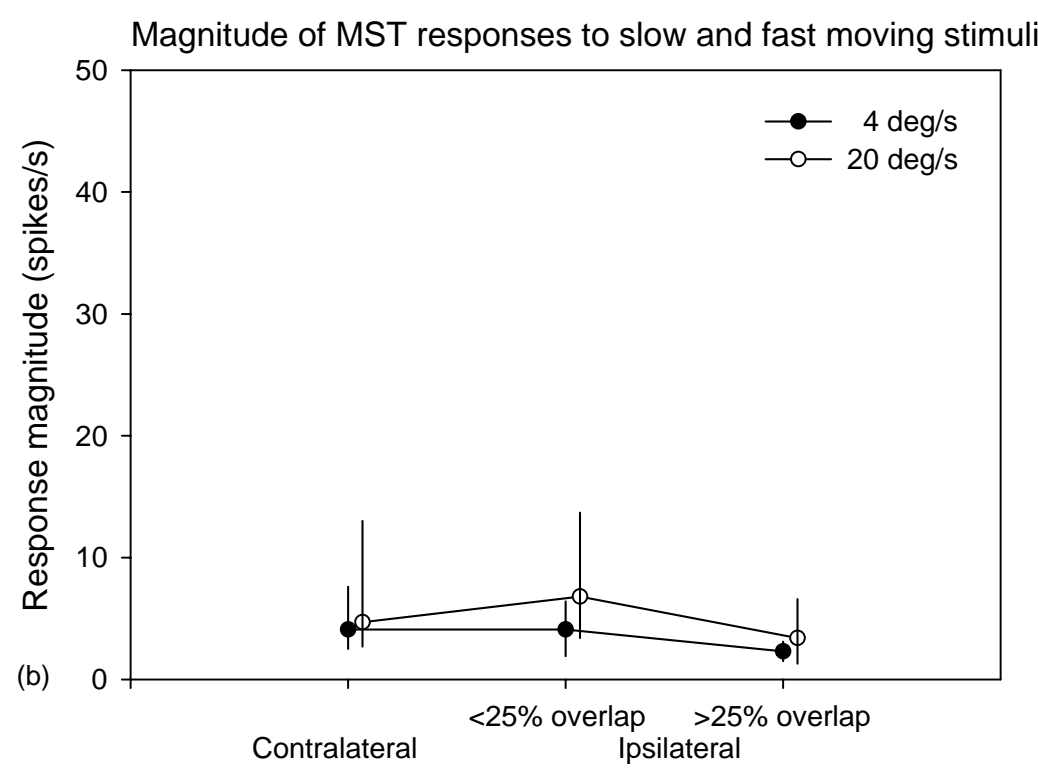

Position of stimulus relative to field defect

Fig. 3. Median response magnitudes to slow and fast moving stimuli in areas MT and MST in the presence and absence of striate cortex lesions, calculated over a $1000 \mathrm{~ms}$ epoch. Bars indicate interquartile ranges.

tend not to support this model, but the critical question is whether or not significantly higher proportions of neurons respond better to fast-moving stimuli than to slow-moving stimuli, and with shorter latency than with longer latency, in MT ipsilateral to a striate cortex lesion compared to MT contralateral to a lesion. This was tested by means of hierarchical log-linear analysis (Bishop, Fienberg, \& Holland, 1975; Howell, 2002).

\subsubsection{Log-linear analysis of speed preference}

The responses of MT and MST neurons in our sample were categorized according to cortical Area (MT or MST), preferred Speed (i.e. whether the neurons responded better to slow or to fast movement, based on differential response magnitudes), and the position both of the neuron relative to the lesion and the stimulus relative to the scotoma (Position, namely contralateral, ipsilateral with $25 \%$ or less of 
Table 4

Analysis of MT and MST speed preferences in macaque monkeys with striate cortex lesions

(a) The numbers of neurons which responded better to slow- or to fast-moving stimuli in lesioned and control hemispheres pooled across monkeys

\begin{tabular}{|c|c|c|c|c|c|}
\hline \multirow[t]{2}{*}{ Area } & \multirow[t]{2}{*}{ Speed preference $(\%)$} & \multicolumn{3}{|c|}{ Position of stimulus relative to field defect } & \multirow[t]{2}{*}{ Total } \\
\hline & & Contralateral & Ipsilateral $(<25 \%$ overlap $)$ & Ipsilateral (>25\% overlap) & \\
\hline \multirow[t]{2}{*}{ MT } & 4 & 5 & 4 & 5 & 14 \\
\hline & 20 & 17 & 8 & 6 & 31 \\
\hline Total & & 22 & 12 & 11 & 45 \\
\hline \multirow[t]{2}{*}{ MST } & 4 & 6 & 5 & 3 & 14 \\
\hline & 20 & 13 & 27 & 4 & 44 \\
\hline Total & & 19 & 32 & 7 & 58 \\
\hline Column total & & 41 & 44 & 18 & 103 \\
\hline
\end{tabular}

(b) Tests of marginal association

\begin{tabular}{llll}
\hline Effect & d.f. & \multicolumn{1}{c}{ G } & $P$ \\
\hline Area & 2 & 1.645 & $0.1996 \mathrm{~ns}$ \\
Speed preference & 1 & 22.261 & $0.0000^{* * *}$ \\
Position & 2 & 13.135 & $0.0014^{* *}$ \\
Area $\times$ Position & 2 & 8.904 & $0.0117^{*}$
\end{tabular}

(c) Collapsed data (ignoring the Area $\times$ Position interaction, which was due to sampling bias)

\begin{tabular}{|c|c|c|c|c|}
\hline \multirow[t]{2}{*}{ Speed preference $(\% / s)$} & \multicolumn{3}{|c|}{ Position of stimulus relative to field defect } & \multirow[t]{2}{*}{ Total } \\
\hline & Contralateral & Ipsilateral $(<25 \%$ overlap $)$ & Ipsilateral $(>25 \%$ overlap) & \\
\hline 4 & $11(11)$ & $9(12)$ & $8(5)$ & 28 \\
\hline 20 & $30(30)$ & $35(32)$ & $10(13)$ & 75 \\
\hline Total & 41 & 44 & 18 & 103 \\
\hline
\end{tabular}

Expected frequencies for the standard test of independence are given in brackets.

$$
\begin{aligned}
& { }^{*} P<0.05 . \\
& { }^{* *} P<0.01 . \\
& \text { *** } P<0.001 .
\end{aligned}
$$

the stimulus inside the scotoma, and ipsilateral with more than $25 \%$ of the stimulus inside the scotoma), as shown in Table 4(a). The proportions of responses classified as preferring slow- and fast-moving stimuli in areas MT and MST in the presence and absence of striate cortex lesions are plotted in Fig. 4.

The results of a hierarchical log-linear analysis are summarized in Table 4(b). There was a significant effect of (i.e. a non-random distribution with respect to) Speed ( $G=22.26$, d.f. $=1, P<0.001$ ), reflecting the fact that roughly $75 \%$ of neurons responded more vigorously to faster movement than to slower movement, but there was no interaction of preferred Speed with Area (reflecting the fact that similar proportions of neurons responded more strongly to the faster stimuli in areas MT and MST), and no interaction of preferred Speed with Position (indicating that the proportions of neurons responding to the faster or the slower stimuli was unaffected by the position of the neuron and the stimulus relative to the field defect). There was, however, a significant interaction of Area with Position $(G=8.9$, d.f. $=2$, $P<0.05)$. This reflects a sampling bias in the number of neurons in MST with receptive fields 'mainly outside' the field defect $(n=32)$, which can be attributed to the fact that neurons with relatively large receptive fields (as is the case for MST neurons relative to MT neurons) tend to be easier to find, particularly in cortical areas ipsilateral to striate cortex lesions where it is more likely that part of the receptive field is outside the field defect. Critically, there was no significant Speed $\times$ Position interaction (see Fig. 4), indicating that the striate cortex lesions did not selectively impair responses to slow-moving stimuli in the way one would have expected if the model proposed by ffytche et al. (1995) were correct.

\subsubsection{Log-linear analysis of response latency}

The responses of MT and MST neurons in our sample were also categorized according to whether their Latency was short (100 ms or less) or long (more than $100 \mathrm{~ms}$ ) as well as by stimulus Speed (slow, $4 \%$ s, or fast, $20^{\circ} / \mathrm{s}$ ), and by Position, both of the neuron relative to the lesion and the stimulus relative to the scotoma as described above. The cut-off of $100 \mathrm{~ms}$ between short and long latencies was adopted because it was the modal latency modal latency in our sample of responses. Given the substantially different latencies of MT and MST neurons the two types of neurons were considered to be heterogeneous in this respect, and so analyzed separately.

The data for MT neurons are shown in Table 5(a) and the results of hierarchical log-linear analysis are summarized in Table 5(b). There was no significant effect of stimulus Speed (as roughly the same number of responses were gathered to 
Proportions of MT neurons classified as preferring slow and fast moving stimuli

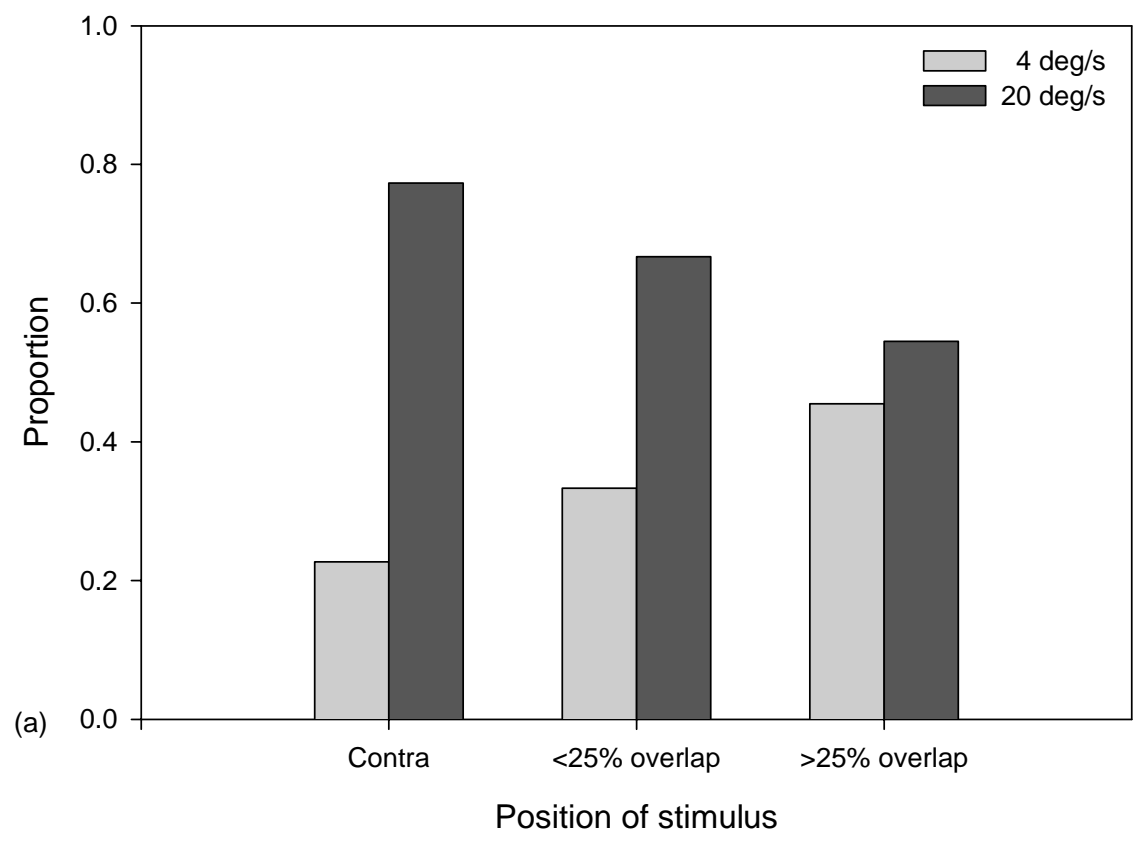

Proportions of MST neurons classified as preferring slow and fast moving stimuli

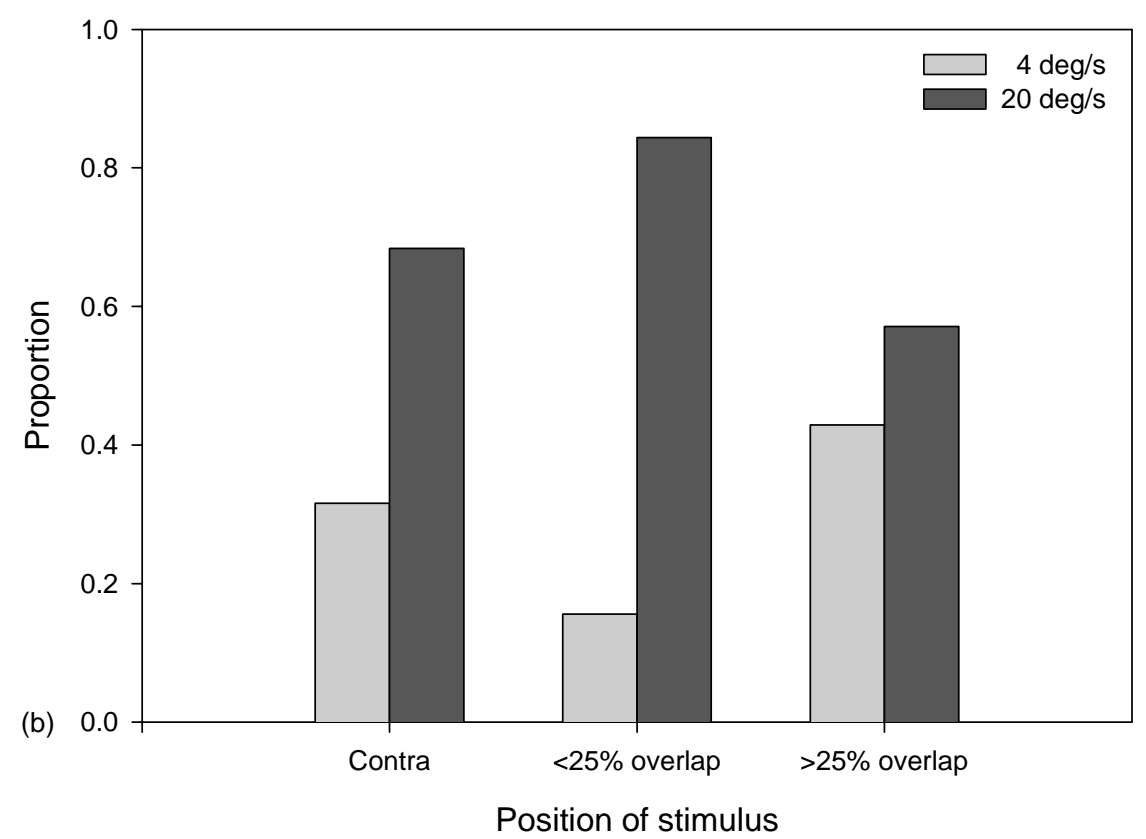

Fig. 4. Proportions of neurons classified as preferring slow and fast moving stimuli in areas MT and MST in the presence and absence of striate cortex lesions, calculated from the data presented in Table 4(a). Responses to slow-moving stimuli were not abolished by striate cortex lesions; if anything, their proportions increased as the overlap of the stimulus with the scotoma increased, though the interaction between speed preference and position was not statistically significant (see text for details). 
Table 5

Analysis of response latencies of MT neurons in macaque monkeys with striate cortex lesions

(a) The numbers of neurons responding with short or long latencies to slow and fast stimuli in lesioned and control hemispheres, pooled across monkeys

\begin{tabular}{|c|c|c|c|c|c|}
\hline \multirow[t]{2}{*}{ Stimulus speed $(\%$ s) } & \multirow[t]{2}{*}{ Response latency (ms) } & \multicolumn{3}{|c|}{ Position of stimulus relative to field defect } & \multirow[t]{2}{*}{ Total } \\
\hline & & Contralateral & Ipsilateral ( $<25 \%$ overlap) & Ipsiliateral (>25\% overlap) & \\
\hline \multirow[t]{2}{*}{4} & $<100$ & 12 & 3 & 2 & 17 \\
\hline & $>100$ & 7 & 8 & 7 & 22 \\
\hline Total & & 19 & 11 & 9 & 39 \\
\hline \multirow[t]{2}{*}{20} & $<100$ & 13 & 4 & 0 & 17 \\
\hline & $>100$ & 9 & 6 & 9 & 24 \\
\hline Total & & 22 & 10 & 9 & 41 \\
\hline Column total & & 41 & 21 & 18 & 80 \\
\hline
\end{tabular}

(b) Tests of marginal association

\begin{tabular}{|c|c|c|c|c|}
\hline Effect & d.f. & $G$ & $P$ & \\
\hline Position & 2 & 11.090 & $0.0039^{* * *}$ & \\
\hline Latency & 1 & 1.807 & $0.1789 \mathrm{~ns}$ & \\
\hline Latency $\times$ Position & 2 & 14.959 & $0.0006^{* * *}$ & \\
\hline \multicolumn{5}{|c|}{ (c) Collapsed table (best model derived from hierarchical log-linear analysis) } \\
\hline \multirow[t]{2}{*}{ Response latency } & \multicolumn{3}{|c|}{ Position of stimulus relative to field defect } & \multirow[t]{2}{*}{ Total } \\
\hline & Contralateral & Ipsilateral $(<25 \%$ overlap $)$ & Ipsilateral (>25\% overlap) & \\
\hline$<100 \mathrm{~ms}$ & 25 (17.4) & $7(8.9)$ & $2(7.7)$ & 34 \\
\hline$>100 \mathrm{~ms}$ & $16(23.6)$ & $14(12.1)$ & $16(10.3)$ & 46 \\
\hline Total & 41 & 21 & 18 & 39 \\
\hline
\end{tabular}

Expected frequencies for the standard test of independence are given in brackets.

${ }^{*} P<0.05, * * P<0.01, * * * P<0.001$.

stimuli of each speed), and no significant effect of Latency (indicating that roughly the same proportion of neurons responded with short latency as with long latency), but there was a significant effect of Position $(G=11.09$, d.f. $=2$, $P<0.01$; reflecting the distribution of responses in the sample, namely fewer responses gathered from MT ipsilateral to striate cortex lesions, especially 'mainly inside' the field defect, than from contralateral MT).

There are two important results. The first is that there was no significant interaction of Speed with Latency, thus providing no evidence of the strict association between stimulus speed and response latency asserted by ffytche et al. (1995), namely that MT neurons respond to fast movement with short latency, and to slow movement with long latency. Secondly, there is a highly significant interaction between Position and Latency $(G=14.96$, d.f. $=2, P<0.001)$, indicating that proportionately more neurons responded with short latency in MT contralateral to a striate cortex lesion, and proportionately fewer neurons responded with short latency in MT ipsilateral to a lesion, particularly 'mainly inside' the scotoma, than would be expected by chance. This is evident in the table of data collapsed across stimulus Speed given in Table 5(c) and plotted in Fig. 5(a), and it is exactly the opposite of what would be predicted if responses with long latencies were mediated exclusively by the geniculo-striate route to MT, and responses with short latency were mediated exclusively by a sub-cortical route. The proportions of responses classified as short and long latency in area MT in the presence and absence of striate cortex lesions, collapsed across stimulus speeds, are presented in Fig. 5(a).

The corresponding data for MST neurons are presented in Table 6(a). Hierarchical log-linear analysis, summarized in Table 6(b), revealed no significant effect of Speed (as roughly the same number of responses were sampled at each one), but highly significant effects of Position ( $G=34.93$, d.f. $=2, P<0.001$; reflecting the uneven sampling distribution of MST neurons among the three positions) and Latency $(G=28.25$, d.f. $=1, P<0.001$; reflecting the fact that the majority, i.e. $75 \%$, of MST responses latencies were $>100 \mathrm{~ms}$ ). Again, there was no significant interaction of Latency and Speed, providing no evidence of a strict association between fast movement and short latency, and between slow movement and long latency. The critical result is the absence of a significant interaction of Latency with Position providing no evidence for a selective impairment of long-latency responses to fast movement in neurons ipsilateral to striate cortex lesions. The proportions of responses classified as short and long latency in area MST in the presence and absence of striate cortex lesions, collapsed across stimulus speeds, are presented in Fig. 5(b). 
Proportions of MT neurons classified as responding with short and long latency

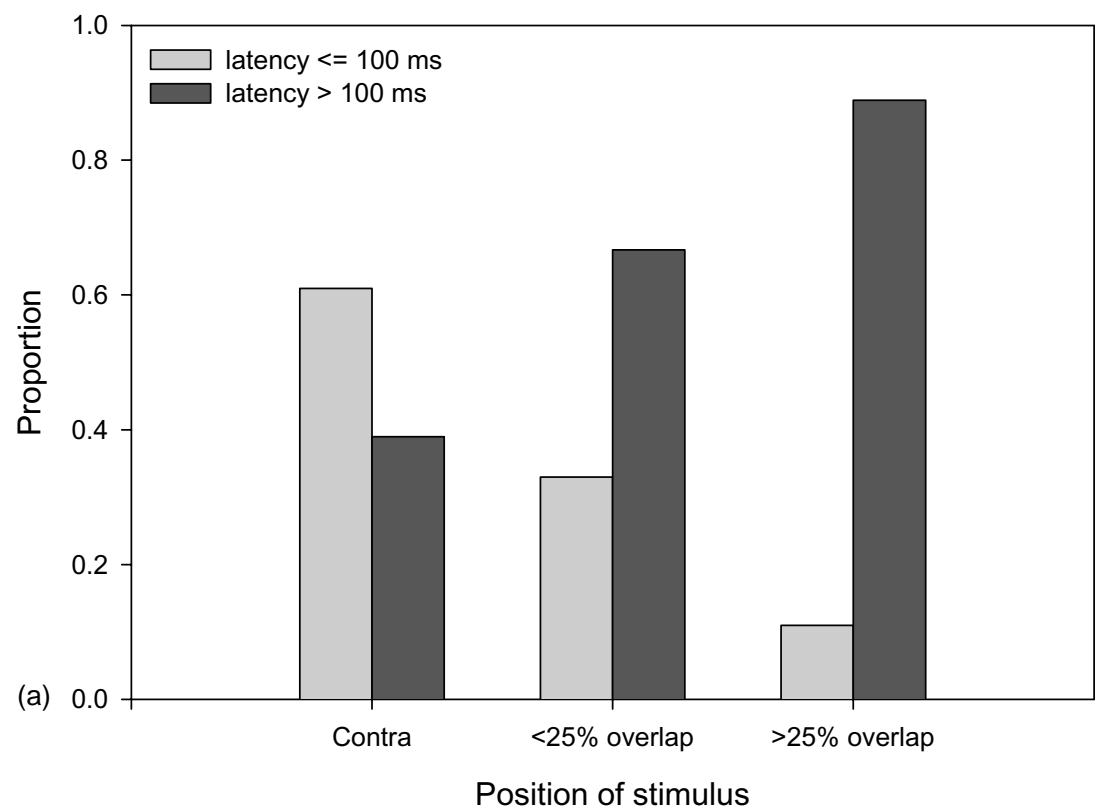

Proportions of MST neurons classified as responding with short and long latency

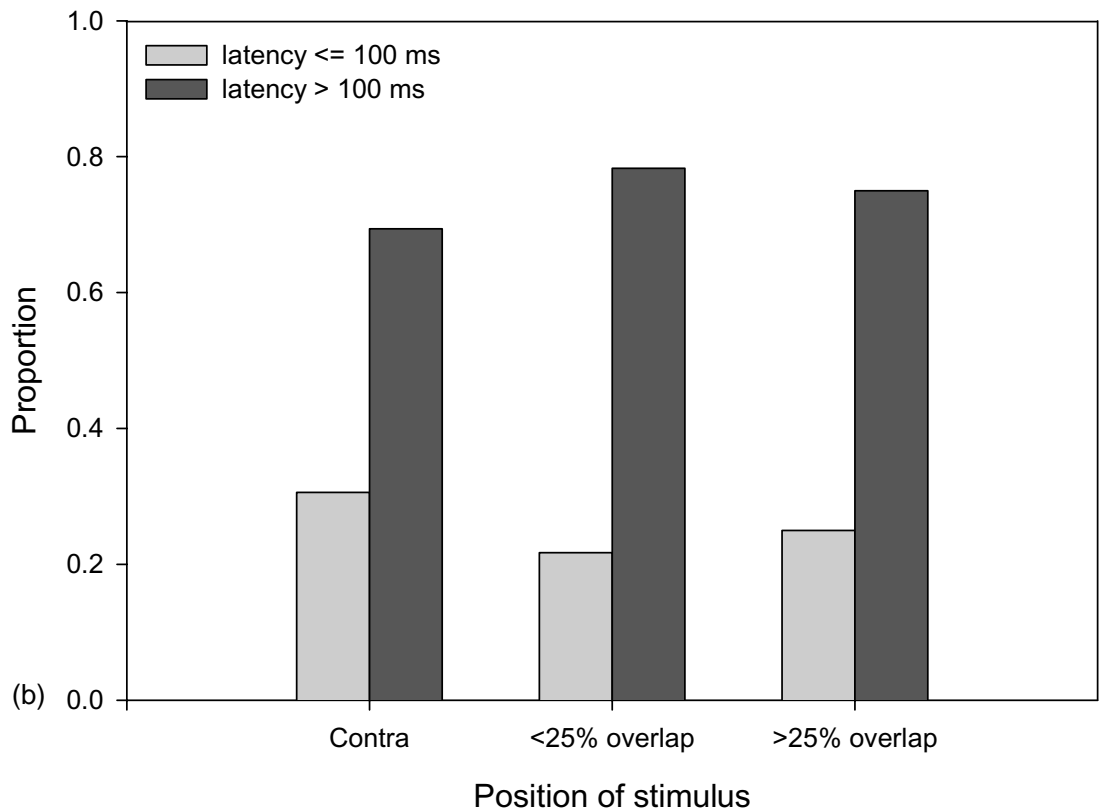

Fig. 5. Proportions of neurons classified as responding with short and long latency in areas MT and MST in the presence and absence of striate cortex lesions, collapsed across stimulus speeds, calculated from the data presented in Table 5(c) and 6(c) respectively. Long-latency responses in area MT were not abolished by striate cortex lesions; in fact, their proportions increased as the overlap of the stimulus with the scotoma increased, and the interaction between response latency and position was highly significant statistically (see text for details). The proportions of short and long latency responses in area MST were not affected by striate cortex lesions. 
Table 6

Analysis of response latencies of MST neurons in macaque monkeys with striate cortex lesions

(a) The numbers of neurons responding with short or long latencies to slow and fast stimuli in lesioned and control hemispheres, pooled across monkeys

\begin{tabular}{|c|c|c|c|c|c|}
\hline \multirow[t]{2}{*}{ Stimulus speed $(\% / s)$} & \multirow[t]{2}{*}{ Response latency } & \multicolumn{3}{|c|}{ Position of stimulus relative to field defect } & \multirow[t]{2}{*}{ Total } \\
\hline & & Contralateral & $\begin{array}{l}\text { Ipsilateral } \\
\text { (<25\% overlap) }\end{array}$ & $\begin{array}{l}\text { Ipsilateral } \\
\text { (>25\% overlap) }\end{array}$ & \\
\hline 4 & $\begin{array}{l}<100 \mathrm{~ms} \\
>100 \mathrm{~ms}\end{array}$ & $\begin{array}{r}7 \\
11\end{array}$ & $\begin{array}{r}7 \\
22\end{array}$ & $\begin{array}{l}0 \\
5\end{array}$ & $\begin{array}{l}14 \\
38\end{array}$ \\
\hline Total & & 18 & 29 & 5 & 52 \\
\hline 20 & $\begin{array}{l}<100 \mathrm{~ms} \\
>100 \mathrm{~ms}\end{array}$ & $\begin{array}{r}4 \\
14\end{array}$ & $\begin{array}{r}6 \\
25\end{array}$ & $\begin{array}{l}3 \\
4\end{array}$ & $\begin{array}{l}13 \\
43\end{array}$ \\
\hline Total & & 18 & 31 & 7 & 56 \\
\hline Column total & & 36 & 60 & 12 & 108 \\
\hline
\end{tabular}

(b) Tests of marginal association

\begin{tabular}{lrrl}
\hline Effect & d.f. & $G$ & $P$ \\
\hline Position & 2 & 34.932 & $0.0000^{* * *}$ \\
Latency & 1 & 28.255 & $0.0000^{* * *}$ \\
Latency $\times$ Position & 2 & 0.934 & $0.6270 \mathrm{~ns}$
\end{tabular}

(c) Collapsed data (best model derived from hierarchical log-linear analysis)

\begin{tabular}{lllll}
\hline Response latency & \multicolumn{2}{l}{ Position of stimulus relative to field defect } & \multicolumn{2}{c}{ Total } \\
\cline { 2 - 4 } & Contralateral & Ipsilateral $(<25 \%$ overlap) & Ipsilateral (>25\% overlap) \\
\hline$<100 \mathrm{~ms}$ & $11(9)$ & $13(15)$ & $3(3)$ & 27 \\
$>100 \mathrm{~ms}$ & $25(27)$ & $47(45)$ & $9(9)$ & 81 \\
Total & 36 & 60 & 12 & 108 \\
\hline
\end{tabular}

Expected frequencies for the standard test of independence are given in brackets.

$$
{ }^{*} P<0.05, * * P<0.01 \text {, *** } P<0.001 \text {. }
$$

\subsection{Responses to static stimuli}

It is important that the response magnitudes and latencies analyzed in the preceding section can be attributed to the movement of the random dot patterns, as opposed to their onset. This particularly applies to MT neurons, whose responses are significantly shorter to onset and more vigorous contralateral to a striate cortex lesion than ipsilateral to a lesion. The responses in MT to the optimal moving pattern at each speed were therefore compared with responses to static random dot patterns of the same dot size and density, which had been interleaved with the moving stimuli in pseudo-random order. For this purpose, responsiveness was measured relative to a blank background as $d^{\prime}$ (a much more sensitive measure than response magnitude), defined as the difference between the mean firing rates in the two conditions, normalized by the geometric mean (i.e. root mean square) of their variances. As responses to static stimuli tend to be transient, values of $d^{\prime}$ were calculated from firing rates determined for a $200 \mathrm{~ms}$ epoch beginning with the onset of the stimulus.

Fig. 6(a) is a scatter plot showing $d^{\prime}$ for a moving pattern in the preferred direction versus the blank background plotted against $d^{\prime}$ for the static pattern versus the blank background, for every MT neuron sampled and for each speed of movement. Clearly, the majority of neurons responded preferentially to the moving patterns. The mean values of $d^{\prime}$ calculated from the responses of MT neurons for each of combination of Position and Speed (static, slow and fast) are plotted in Fig. 6(b). It is clear that the neurons in our sample exhibited no significant responses to static random dot patterns, i.e. it is not possible to discriminate between a static random dot pattern and a blank background on the basis of their firing rates, regardless of the position of the stimulus with respect to the field defect. This is a striking finding, given that MT neurons in unlesioned monkeys exhibit significant, though weak, responses to the presentation of static bars or slits (mean response magnitude of 5.8 spikes/s (Albright, 1984)), but it may be related to the well-documented existence of inhibitory regions which surround the classical receptive fields of MT neurons (Allman, Miezen, McGuiness, 1985; Lagae, Gulyas, Raiguel, \& Orban, 1989; Tanaka et al., 1986), into which the static random dot patterns may have encroached. If this is the case, it would imply that the relative influence of the excitatory 'centres' and inhibitory surrounds varies according to the speed of motion depicted by the stimulus (see Xiao, Raiguel, Marcar, \& Orban, 1998).

The MT neurons in our sample did not respond significantly to static random dot patterns, but they did respond 


\section{Responses of MT neurons to moving and static stimuli compared}
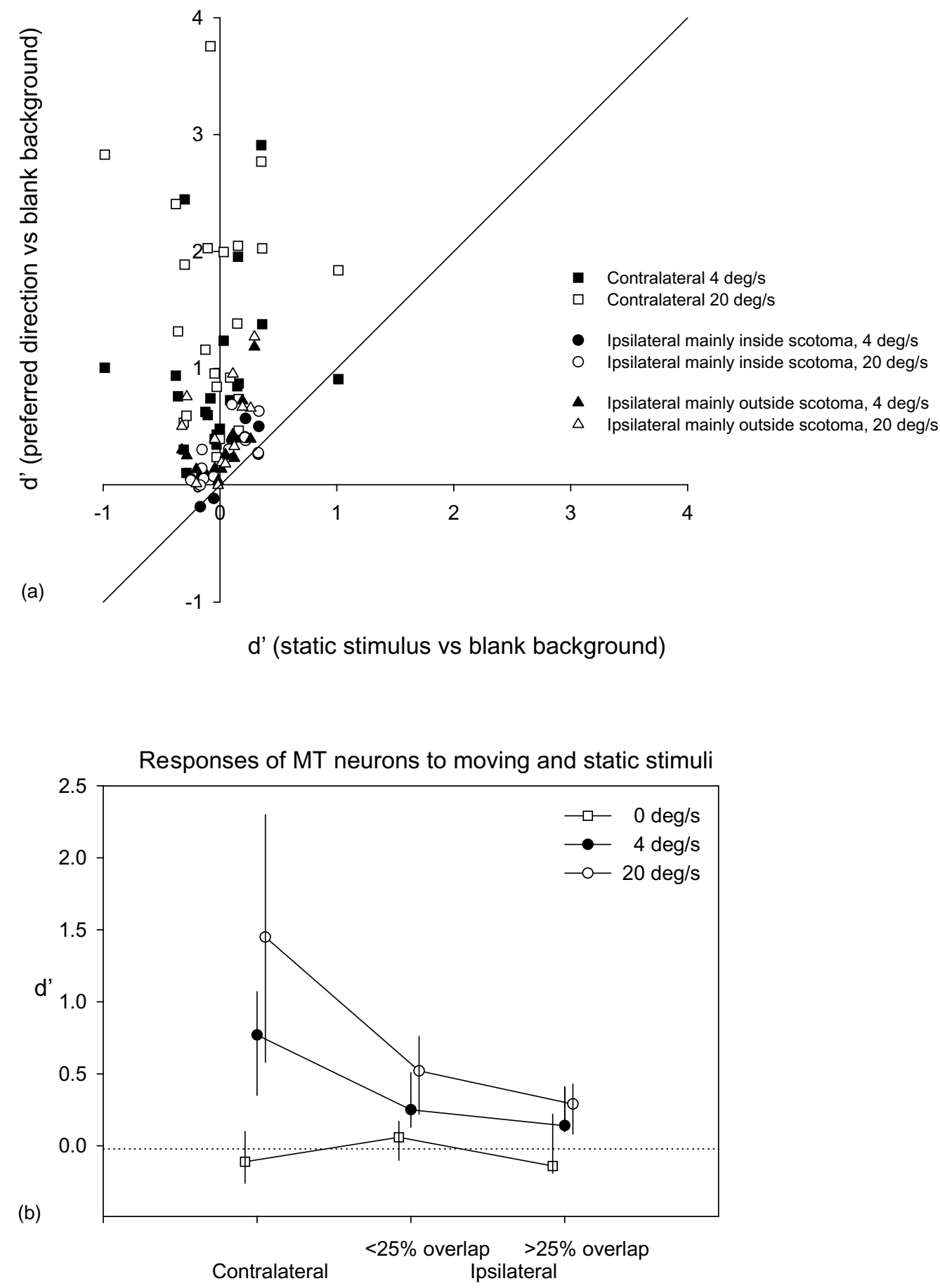

Position of stimulus relative to field defect

Fig. 6. Responses of MT neurons to moving and static stimuli compared. The index of responsiveness is $d^{\prime}$, calculated from spike rates in a $200 \mathrm{~ms}$ epoch starting with stimulus onset. 
significantly to moving random dot patterns in all positions (though, as we have already established, the responses were strongest in MT in the unlesioned hemisphere and decreased as the overlap of the stimulus and the scotoma increased in the lesioned hemisphere). These results indicate that the responses analyzed in the preceding sections were due to the motion of the stimuli and not their onset. The reduction in average sensitivity with stimulus overlap with the scotoma correlates with an increase in average response latency (shown in Fig. 2), mirroring the observation in intact monkeys that response latency of MT neurons is inversely correlated with response strength (Raiguel et al., 1999).

\section{Discussion}

ffytche et al. (1995) (see also Zeki, 1998) proposed that visual motion perception is mediated by two distinct pathways between the retina and cortical area MT, namely a 'direct' pathway via sub-cortical nuclei that bypasses striate cortex and is specialized for processing fast motion with relatively short latency, and an 'indirect' cortical pathway via striate cortex that is specialized for processing slow motion with relatively long latency. We tested this by analyzing the magnitudes and latencies of responses to moving stimuli in area MT of monkeys with striate cortex lesions. In the unlesioned hemisphere contralateral to a V1 lesion, MT response latencies and magnitudes were indistiguishable from those reported previously for MT neurons of monkeys without V1 lesions. We also found that contralateral to striate cortex lesions there was no significant association between the speed of the stimulus and the latency of MT neurons' responses to motion, i.e. there was no evidence that MT neurons in an unlesioned hemisphere respond to fast-moving stimuli with relatively short latency, and to slow-moving stimuli with long latency. V1 lesions did not abolish neural responses to slow-moving stimuli in ipsilateral MT; nor did they abolish long-latency responses to either slow- or fast-moving stimuli (in fact, the average response latency in MT ipsilateral to a lesion was significantly longer than in MT of the unlesioned hemisphere). Thus, responses of MT neurons to slow- and fast-moving stimuli were not dissociated by striate cortex lesions; rather, the greater the overlap of the stimulus with the field defect, the weaker and more sluggish were the responses of MT neurons to moving stimuli of either speed. All these findings are incompatible with the model of dynamic parallelism proposed by ffytche et al. (1995). This model took into account three lines of evidence: response latencies in MT+ to slow and fast moving stimuli in the presence and the absence of striate cortex lesions (ffytche et al., 1995, 1996); a proposed direct anatomical projection from the dLGN to area MT (Fries, 1981); and a double dissociation between a patient with damaged striate cortex who is relatively insensitive to slow motion (Barbur et al., 1993) and a patient with damaged MT+ rendered relatively insen- sitive to fast motion (Hess et al., 1989). We shall consider each in turn.

\subsection{Response latencies}

Using a combination of EEG and magnetoencephalography (MEG) in normal human subjects, ffytche et al. (1995) found that responses to slow stimuli $(<6 \%$ s) were evoked in striate cortex before MT + , whereas responses to fast stimuli $(22 \%)$ were evoked in MT+ before striate cortex, implying that visual information is routed to MT+ via one of two parallel routes depending on the speed. This conflicted with previous work, which showed that activity recorded with EEGs in the striate cortex always preceded that in extrastriate cortex (Drasdo, Edwards, \& Thompson, 1993; Probst, Plendl, Paulus, Wist, \& Scherg, 1993); and it could not subsequently be replicated (Anderson et al., 1996). ffytche et al. (1995) supported their interpretation by pointing to similarities between their results and the distribution of response latencies recorded from single units in area MT of macaque by Raiguel et al. (1989). In the latter study, bars (or slits) were moved past the receptive field, and the response latency was inferred from a graph in which the apparent displacement of the receptive field was plotted against stimulus speed, the slope of which is equivalent to the latency (spatial lag plot Bishop, Coombs, Henry, 1971). The shortest latencies recorded in this way from MT and from V1 were 35 and $45 \mathrm{~ms}$, respectively. ffytche et al. (1995) argued that this was consistent with their model (overlooking the fact that the median latency in MT, at $94 \mathrm{~ms}$, was longer than that in $\mathrm{V} 1$, at $85 \mathrm{~ms}$ ). A particular drawback of the method, however, is that it relies on the assumption that response latency is constant at all speeds, which is almost certainly not the case for MT neurons as they are distinctly tuned to particular speeds of movement (Lagae, Raiguel, \& Orban, 1993; Rodman \& Albright, 1987), and their response latencies tend to be inversely correlated with their firing rates (Raiguel et al., 1999). If an MT neuron responded with relatively shorter latency to faster stimuli, and with longer latency to slower moving stimuli, simply because it was tuned to respond better to the faster speed, then the slope of the spatial lag plot would be reduced (because the spatial lag is proportional to the response latency, as well as to the speed of movement), yielding an underestimate of latency. Conversely, if a V1 neuron responded with relative shorter latency to a slower stimulus than to a fast one because it was tuned to respond better to slower speeds, the slope of the spatial lag plot would be enhanced, producing an overestimate of the response latency. This could easily account for the fact that the shortest latencies were apparently recorded from MT and not V1, as MT neurons tend to be tuned to faster speeds than V1 neurons (Maunsell \& van Essen, 1983a,b; Mikami, Newsome, \& Wurtz, 1986; Orban, Kennedy, \& Bullier, 1986). In the present study, this potential confound was avoided by measuring the latencies of responses to moving random dot patterns presented in a window centered 
on the receptive field, with a clear motion onset to which neural responses could be time-locked precisely, and which elicited responses which were not contaminated by transient responses to pattern onset. When used to compare explicitly the responses of MT neurons to slow- and fast-moving patterns, there was no evidence for the existence of a clear-cut association between fast movement and short latencies, and slow movement and long latencies, in MT of an unlesioned hemisphere contralateral to a striate lesion.

Further evidence used to support dynamic parallelism was the fact that long-latency EEG responses in MT+ to slow movement were absent from the damaged hemisphere of a patient with striate cortex lesions, despite the fact that fast motion elicited responses similar to those found in normal subjects (ffytche et al., 1996). This is also controversial, as at least three independent groups have been unable to verify the findings, using EEG (Benson, Guo, \& Hardiman, 1999; Rao, Nobre, \& Cowey, 1999) and the more sensitive method of MEG (Holliday et al., 1997). In the latter study, a bimodal distribution of response latencies were recorded from $\mathrm{MT}+$ in the intact hemisphere, but it was the population of responses with shorter latencies (not longer ones) that were absent in the damaged hemisphere. This corresponds to our finding that the proportion of long latency responses in MT in the lesioned hemisphere was greater, and the average latency significantly and substantially longer, than in the intact hemisphere. If anything, this indicates that the striate cortex might be necessary for mediating short-latency responses in area MT, which is incompatible with the model.

\subsection{Anatomical pathways}

In order to account for short latency responses to moving stimuli in area MT+, ffytche et al. (1995) proposed that motion signals were relayed from the retina to MT via a direct retino-geniculo-MT projection, bypassing V1, through which responses to fast motion might be routed selectively. This was based on neuroanatomical tracing experiments in macaques by Fries (1981), who labelled dLGN neurons retrogradely with horseradish peroxidase (HRP) injected into extrastriate cortex, including upper superior temporal sulcus.

There are good reasons to doubt the existence of such a pathway. First, several other studies have failed to replicate the finding (Benevento \& Yoshida, 1981; Maunsell \& van Essen, 1983a,b; Standage \& Benevento, 1983; Yoshida \& Benevento, 1981), even when more sensitive tracers were used (Johnson, 1999; Sorensen \& Rodman, 1999). Secondly, it is incompatible with the finding that neurons in MT of monkeys with combined striate cortex and superior colliculus lesions lose all their ability to respond to moving stimuli (Rodman et al., 1989, 1990), as it implies that the responses in MT which persist in the absence of V1 cannot be sustained by a putative pathway direct from the retina to the dLGN. The likeliest explanation of Fries' result is that some of the HRP injected into MT encroached beyond its boundaries into underlying white matter or into adjacent area V4t, which does receive direct projections from the dLGN (Kisvarday, Cowey, Stoerig, \& Somogyi, 1991; Lysakowski, Standage, \& Benevento, 1988; Yoshida \& Benevento, 1981).

Could short latency responses be mediated by the colliculo-pulvinar pathway? Johnson (1999) injected the transneuronal tracer wheatgerm-agglutinated HRP (WGA-HRP), into the superior colliculus of a macaque monkey with a long-standing, unilateral striate cortex lesion, which produced anterograde labelling of the interlaminar and S-layers of the LGN, the pregeniculate nucleus, and the inferior pulvinar, but none in ipsilateral extrastriate cortex, including MT. This could imply that the route via the superior colliculus to MT involves more than one synapse in the pulvinar nucleus, as has been shown in the owl monkey (Stepniewska, Qi, \& Kaas, 1999), or at least it does not establish the existence of a monosynaptic relay, without which this pathway is unlikely to be capable of mediating very short latency responses. On purely anatomical grounds, therefore, there is no reason yet to suppose that the sub-cortical route is more 'direct' than the geniculo-striate route, or that it should convey signals to MT any faster.

\subsection{Double dissociations}

The third line of evidence used to support dynamic parallelism was the fact that the ability to discriminate slow and fast moving stimuli can apparently be doubly dissociated in patients with brain damage. Barbur et al. (1993) reported that a patient with a unilateral V1 lesion (patient GY) could discriminate the direction of motion of bars moved quickly, but not slowly, in his field defect under conditions in which MT+ (and V3) was activated; whereas Hess et al (Hess et al., 1989) found that a patient with bilateral lesions affecting MT+ (patient LM (Zihl et al., 1983)) could only discriminate slow $\left(<6^{\circ} / \mathrm{s}\right)$ but not fast motion. To some extent, this was supported by the results of experiments with macaque monkeys which showed that directional selectivity of MT neurons was preserved after striate cortex lesions (Girard et al., 1992; Rodman et al., 1989), indicating that motion signals could be routed to MT via an extra-geniculostriate pathway (most likely the colliculo-pulvinar route, Rodman et al., 1990). Two recent findings cast doubt on this conclusion. The first was that although MT neurons are capable of discriminating the direction of movement of bars moved through their receptive fields in monkeys with striate cortex lesions, they are unable to discriminate the direction of motion depicted in random dot kinematograms (Azzopardi et al., 1998). Secondly, and in an analogous way, patients with striate cortex lesions are able to discriminate the direction of movement of bars moved through their field defects, but not of the direction of motion depicted in random dot kinematograms, even when the trajectories of the dots are $100 \%$ correlated (Azzopardi \& Cowey, 2001; Barton \& Sharpe, 1997; Cowey \& Azzopardi, 2001). Azzopardi \& Cowey (2001) argued that moving bars confound position with movement, and that GY's ability to discriminate motion 
direction reported by Barbur et al. (1993) could have been based on positional cues, as opposed to motion processing. If they are correct, it would imply that motion perception is mediated entirely via the geniculo-striate route to MT and that there is therefore no need to postulate a two-route model for analysis of visual motion under normal conditions.

\subsection{Effects of V1 lesions on responses in MST}

We also considered the responses of neurons in MST. This is relevant because it is not possible to distinguish between the contribution of MT and MST to responses recorded from MT+ with EEG or MEG. We found that contralateral to a striate cortex lesion, response latencies were similar to those reported previously for MST neurons in monkeys without V1 lesions, though the responses were somewhat weaker (which may be due to differences between the studies in the measure of response strengths and in the stimulus parameters used); and we found no significant association between response latency and stimulus speed (the majority of response latencies recorded from MST contralateral to a striate cortex lesion were longer than $100 \mathrm{~ms}$, irrespective of stimulus speed). Ipsilateral to a V1 lesion response latencies and magnitudes were not significantly different from the contralateral, unlesioned side. Had our results from MT been consistent with dynamic parallelism, we would have concluded that the contribution from MST to EEGs recorded from MT+ by ffytche et al. (1995) must have been too weak to contaminate or mask the signals originating in MT. However, we are still left with a puzzle: Why did V1 lesions apparently not affect the responses of ipsilateral MST neurons? One possibility is that the stimuli we used to test MST responses were far from optimal. We think this can be discounted, because the response magnitudes and latencies which we recorded were similar to those published by other experienced investigators, and because many of the responses of MST neurons in the hemisphere contralateral to a striate cortex lesion passed the diagnostic positional invariance test (Graziano, Andersen, \& Snowden, 1994; Lagae, Raiguel, \& Orban, 1993). Another possibility is that, as MST neurons have such large receptive fields (Desimone \& Ungerleider, 1986; Tanaka et al., 1986), the neurons in our sample (particularly those from monkeys with partial striate cortex lesions) inevitably pooled responses from MT neurons with receptive fields located beyond the borders of the field defect, providing sufficient input to drive them at near-normal levels. The difficulty for this explanation is that it would be inconsistent with the finding that responses of MT neurons ipsilateral to striate cortex lesions were relatively impaired irrespective of whether the stimulus was presented mainly inside or mainly mainly outside (i.e. up to $100 \%$ outside) the field defect. If both of these explanations can be discounted, then we ought to consider the implication that MST neurons receive substantial inputs which bypass the geniculo-striate route, but as none of the responses recorded from MST in the absence of striate cortex are directionally-selective (Azzopardi et al., 1998) the likelihood is that they are not motion-specific inputs. This raises the further possibility that the residual responses in MT ipsilateral to a striate cortex lesion originate in MST via feedback projections, which would be consistent with the fact that response latencies in MT are as long or longer than those in MST in the lesioned hemisphere (Table 1 and Fig. 2).

\section{Conclusion}

Having recorded the responses of MT and MST neurons to random dot kinematograms in monkeys with striate cortex lesions, we found no evidence for the model of motion perception known as dynamic parallelism proposed by ffytche et al. (1995)—either its premise, which is that MT neurons respond to fast movement with short latency, and to slow movement with long latency —or its predictions, namely that striate cortex lesions should abolish long-latency responses, and abolish responses to slow movement. In line with the results of recent electrophysiological (Azzopardi et al., 1998) and psychophysical (Azzopardi \& Cowey, 2001; Barton \& Sharpe, 1997; Cowey \& Azzopardi, 2001) experiments, our results would be more consistent with a model in which motion perception is mediated entirely by a geniculo-striate route to MT.

\section{Acknowledgements}

This work was supported by grants form the N.I.H. (EY11347), N.S.F. (BNS 9109743) and the Oxford McDonnell-Pew Centre for Cognitive Neuroscience. We thank Brian Benway, Alan Cowey, Shefali Ghandi, Michael Graziano, Scott Regenbogen, and Xintian Hu for their help.

\section{References}

Albright, T. D. (1984). Direction and orientation selectivity of neurons in visual area MT of the macaque. Journal of Neurophysiology, 52, 1106-1130.

Allman, J. M., Miezen, F., \& McGuiness, E. (1985). Direction- and velocity-specific responses from beyond the classical receptive field in the middle temporal visual area (MT). Perception, 14, 105-126.

Anderson, S. J., Holliday, I. E., Singh, K. D., \& Harding, G. F. A. (1996). Localization and functional analysis of human cortical area V5 using magneto-encephalography. Proceedings of the Royal Society, London, B263, 423-431.

Azzopardi, P., \& Cowey, A. (2001). Motion discrimination in cortically-blind patients. Brain, 124, 30-46.

Azzopardi, P., Fallah, M., Gross, C. G., \& Rodman, H. R. (1998). Responses of neurons in visual areas MT and MST after lesions of striate cortex in macaque monkeys. Society for Neuroscience Abstracts, $24,648$.

Azzopardi, P., Fallah, M., Regenbogen, S. E., Gross, C. G., \& Rodman, H. R. (1999). Response latencies of neurons in cortical areas MT and MST in monkeys with striate cortex lesions. Investigative Ophthalmology and Visual Science, 40, S640. 
Baker Jr., C. L., Hess, R. F., \& Zihl, J. (1991). Residual motion perception in a "motion-blind" patient, assessed with limited-lifetime random dot stimuli. Journal of Neuroscience, 11, 454-461.

Barbur, J. L., Watson, J. D., Frackowiak, R. S. J., \& Zeki, S. (1993). Conscious visual perception without V1. Brain, 116, 1293-1302.

Barton, J. J., \& Sharpe, J. A. (1997). Motion direction discrimination in blind hemifields. Annals of Neurology, 41, 255-264.

Beckers, G., \& Homberg, V. (1992). Cerebral visual motion blindness: transitory akinetopsia induced by transcranial magnetic stimulation of human area V5. Proceedings of the Royal Society London, B249, 173178.

Beckers, G., \& Zeki, S. (1985). The consequences of inactivating area V1 and V5 on visual motion perception. Brain, 118, 49-60.

Benevento, L. A., \& Yoshida, K. (1981). The afferent and efferent organization of the lateral geniculo-prestriate pathways in the macaque monkey. Journal of Comparative Neurology, 203, 455-474.

Benson, P. J., Guo, K., \& Hardiman, M. J. (1999). Cortical evoked potentials due to motion contrast in the blind field. Neuroreport, 10, 3595-3600.

Bishop, P. O., Coombs, J. S., \& Henry, G. H. (1971). Responses to visual contours: spatio-temporal aspects of excitation in the receptive fields of simple striate neurons. Journal of Physiology, London, 219, 625-657.

Bishop, Y. M., Fienberg, S. E., \& Holland, P. W. (1975). Discrete multivariate analysis: Theory and practice. Cambridge, MA: The MIT Press.

Britten, K. H., \& van Wesel, R. J. (1998). Electrical microstimulation of cortical area MST biases heading perception in monkeys. Nature Neuroscience, 1, 59-63.

Britten, K. H., Shadlen, M. N., Newsome, W. T., \& Movshon, J. A. (1992). The analysis of visual motion: a comparison of neuronal and psychophysical performance. Journal of Neuroscience, 12, 4745-4765.

Celebrini, S., \& Newsome, W. T. (1994). Neuronal and psychophysical sensitivity to motion signals in extrastriate area MST of the macaque monkey. Journal of Neuroscience, 14, 4109-4124.

Celebrini, S., \& Newstome, W. T. (1995). Microstimulation of extrastriate area MST influences performance on a direction discrimination task. Journal of Neurophysiology, 73, 437-448.

Choi, S., Anand, S., \& Hotson, J. (1995). Transcranial magnetic perturbation of motion and luminance signals in striate and extrastriate cortex. Investigative Ophthalmology and Visual Science, 36, S56.

Cowey, A., \& Azzopardi, P. (2001). Is blindsight motion-blind? In B. de Gelder, E. de Haan, \& C. Heywood (Eds.), Out of mind: Varieties of unconscious processing. Oxford: Oxford University Press.

Desimone, R., \& Ungerleider, L. G. (1986). Multiple visual areas in the caudal superior temporal sulcus of the macaque. Journal of Comparative Neurology, 248, 164-189.

Drasdo, N., Edwards, L., \& Thompson, D. A. (1993). Models of the visual cortex based on visual evoked potentials. In B. Gulyas, D. Ottoson, \& P. E. Roland (Eds.), Function organization of the human visual cortex. Oxford: Pergamon Press.

Duffy, C. J., \& Wurtz, R. H. (1991a). Sensitivity of MST neurons to optic flow stimuli. I. A continuum of response selectivity to large-field stimuli. Journal of Neurophysiology, 65, 1329-1345.

Duffy, C. J., \& Wurtz, R. H. (1991b). Sensitivity of MST neurons to optic flow stimuli. II. Mechanisms of response selectivity revealed by small-field stimuli. Journal of Neurophysiology, 65, 1346-1359.

ffytche, D. H., Guy, C. N., \& Zeki, S. (1995). The parallel visual motion inputs into areas V1 and V5 of human cerebral cortex. Brain, 118, $1375-1394$.

ffytche, D. H., Guy, C. N., \& Zeki, S. (1996). Motion specific responses from a blind hemifield. Brain, 119, 1971-1982.

Fries, W. (1981). The projection from the lateral geniculate nucleus to the prestriate cortex of the macaque monkey. Proceedings of the Royal Society, London, B213, 73-86.

Gallyas, F. (1969). Silver staining of myelin by means of physical development. Orvostucomany, 20, 433-489.
Girard, P., Salin, P. A., \& Bullier, J. (1992). Response selectivity of neurons in area MT of the macaque monkey during reversible inactivation of area V1. Journal of Neurophysiology, 67, 1437-1446.

Graziano, M. S., Andersen, R. A., \& Snowden, R. J. (1994). Tuning of MST neurons to spiral motion. Journal of Neuroscience, 14, 54-67.

Gross, C. G. (1991). Contribution of striate cortex and the superior colliculus to visual function in area MT the superior temporal polysensory area and the inferior temporal cortex. Neuropsychologia, 29, 497-515.

Gross, C. G., Moore, T., \& Rodman, H. R. (2003). Visually-guided behavior after striate cortex lesions in young and adult monkeys and its relation to blindsight in humans. Progress in Brain Research, in press.

Hess, R. F., Baker Jr., C. L., \& Zihl, J. (1989). The 'motion-blind' patient: Low-level spatial and temporal filters. Journal of Neuroscience, 9, 1628-1640

Holliday, I. E., Anderson, S. J., \& Harding, G. F. A. (1997). Magnetoencephalographic evidence for non-geniculostriate visual input to human cortical area V5. Neuropsychologia, 35, 1139-1146.

Hotson, J. S., \& Anand, S. (1999). The selectivity and timing of motion processing in human temporo-parieto-occipital and occipital cortex: a transcranial magnetic stimulation study. Neuropsychologia, 37, 169179.

Hotson, J., Braun, D., \& Herzberg, W. (1994). Transcranial magnetic stimulation of extrastriate cortex degrades human motion direction discrimination. Vision Research, 34, 2115-2123.

Howell, D. C. (2002). Statistical methods for psychology (5th ed.). Pacific Grove, CA: Duxbury.

Johnson, H. (1999). The neurobiological bases of blindsight. D.Phil. Thesis, University of Oxford.

Kawano, K., Shidara, M., Watanabe, Y., \& Yamane, S. (1994). Neural activity in cortical area MST of alert monkey during ocular following responses. Journal of Neurophysiology, 71, 2305-2324.

Kisvarday, Z. F., Cowey, A., Stoerig, P., \& Somogyi, P. (1991). Direct and indirect retinal input into degenerated dorsal lateral geniculate nucleus after striate cortical removal in monkey: Implications for residual vision. Experimental Brain Research, 86, 271-292.

Lagae, L., Gulyas, B., Raiguel, S., \& Orban, G. A. (1989). Laminar analysis of motion information processing in macaque V5. Brain Research, 496, 261-267.

Lagae, L., Raiguel, S. E., \& Orban, G. A. (1993). Speed and direction selectivity of macaque middle temporal neurons. Journal of Neurophysiology, 69, 19-39.

Lagae, L., Maes, H., Raiguel, S., Xiao, D. K., \& Orban, G. A. (1994). Responses of macaque STS neurons to optic flow components: A comparison of areas MT and MST. Journal of Neurophysiology, 71, $1597-1626$

Lysakowski, A., Standage, G. P., \& Benevento, L. A. (1988). An investigation of collateral projections of the dorsal lateral geniculate nucleus and other subcortical structures to cortical areas V1 and $\mathrm{V} 4$ in the macaque monkey: a double label retrograde tracer study. Experimental Brain Research, 69, 651-661.

Malpeli, J. G., \& Baker, F. H. (1975). The representation of the visual field in the lateral geniculate nucleus of Macaca mulatta. Journal of Comparative Neurology, 161, 569-594.

Malpeli, J. G., Lee, D., \& Baker, F. H. (1996). Laminar and retinotopic organization of the macaque lateral geniculate nucleus: Magnocellular and parvocellular magnification functions. Journal of Comparative Neurology, 375, 363-377.

Maunsell, J. H. R., \& van Essen, D. C. (1983a). Functional properties of neurons in middle temporal area of the macaque monkey. I. Selectivity for stimulus direction. Journal of Neurophysiology, 49, 1127-1147.

Maunsell, J. H. R., \& van Essen, D. C. (1983b). The connections of the middle temporal visual area (MT) and their relationship to a cortical hierarchy in the macaque monkey. Journal of Neuroscience, 3, 2563 2586.

Mikami, A., Newsome, W. T., \& Wurtz, R. H. (1986). Motion selectivity in macaque visual cortex. II. Spatiotemporal range of interactions in MT and V1. Journal of Neurophysiology, 55, 1328-1339. 
Moore, T., Rodman, H. R., Repp, A. B., \& Gross, C. G. (1995). Localization of visual stimuli after striate cortex damage in monkeys: Parallels with human blindsight. Proceedings of the National Academy of Sciences of the United States of America, 92, 8215-8218.

Moore, T., Rodman, H. R., Repp, A. B., Gross, C. G., \& Mezrich, R. S. (1996). Greater residual vision in monkeys after striate cortex damage in infancy. Journal of Neurophysiology, 76, 3928-3933.

Moore, T., Rodman, H. R., \& Gross, C. G. (2001). Direction of motion discrimination after early lesions of striate cortex (V1) of the macaque monkey. Proceedings of the National Academy of Sciences of the United States of America, 98, 325-330.

Newsome, W. T., \& Pare, E. B. (1988). A selective impairment of motion perception following lesions of the middle temporal visual area (MT). Journal of Neuroscience, 8, 2201-2211.

Newsome, W. T., Wurtz, R. H., \& Dürsteler, M. R. (1985). Deficits in visual motion processing following ibotenic acid lesions of the middle temporal visual area of the macaque monkey. Journal of Neuroscience, $5,825-840$.

Newsome, W. T., Britten, K. H., \& Movshon, J. A. (1989). Neuronal correlates of a perceptual decision. Nature, London, 341, 52-54.

Orban, G. A., Kennedy, H., \& Bullier, J. (1986). Velocity sensitivity and direction selectivity of neurons in V1 and V2 of the monkey: Influence of eccentricity. Journal of Neurophysiology, 56, 462-480.

Orban, G. A., Lagae, L., Verri, A., Raiguel, S., Xiao, D., Maes, H., \& Torre, V. (1992). First-order analysis of optical flow in monkey brain. Proceedings of the National Academy of Sciences USA, 89, 2595-2599.

Orban, G. A., Lagae, L., Raiguel, S., Xiao, D., \& Maes, H. (1995). The speed tuning of medial superior temporal (MST) cell responses to optic-flow components. Perception, 24, 269-285.

Pasternak, T., \& Merigan, W. H. (1994). Motion perception following lesions of the superior temporal sulcus in the monkey. Cerebral Cortex, 4, 247-259.

Probst, T., Plendl, H., Paulus, W., Wist, E. R., \& Scherg, M. (1993). Identification of the visual motion area (area V5) in the human brain by dipole source analysis. Experimental Brain Research, 93, 345-351.

Rao, A., Nobre, A. C., \& Cowey, A. (1999). Comparison of visual evoked potentials in a patient with V1 lesion and in normal subjects. Society for Neuroscience Abstracts, 25, 1931.

Raiguel, S. E., Lagae, L., Gulyas, B., \& Orban, G. A. (1989). Response latencies of visual cells in macaque areas V1, V2 and V5. Brain Research, 493, 155-159.

Raiguel, S. E., Xiao, D. K., Marcar, V. L., \& Orban, G. A. (1999). Response latency of macaque Area MT/V5 and its relationship to stimulus parameters. Journal of Neurophysiology, 82, 1944-1956.

Rizzo, M., Nawrot, M., \& Zihl, J. (1995). Motion and shape perception in cerebral akinetopsia. Brain, 118, 1105-1127.

Rodman, H. R., \& Albright, T. D. (1987). Coding of stimulus velocity in area MT of the macaque. Vision Research, 27, 2035-2048.

Rodman, H. R., \& Albright, T. D. (1989). Single-unit analysis of pattern-motion selective properties in the middle-temporal visual area (MT). Experimental Brain Research, 75, 53-64.

Rodman, H. R., Gross, C. G., \& Albright, T. D. (1989). Afferent basis of visual response properties in area MT of the macaque. I. Effects of striate cortex removal. Journal of Neuroscience, 9, 2033-2050.

Rodman, H. R., Gross, C. G., \& Albright, T. D. (1990). Afferent basis of visual response properties in area MT of the macaque. II. Effects of superior colliculus removal. Journal of Neuroscience, 10, 11541164.

Saito, H., Yukie, M., Tanaka, K., Hikosaka, K., Fukada, Y., \& Iawai, E. (1986). Integration of direction signals of image motion in the superior temporal sulcus of the macaque monkey. Journal of Neuroscience, 6 , $145-157$.

Salzman, C. D., Britten, K. H., \& Newsome, W. T. (1990). Cortical microstimulation influences perceptual judgements of motion direction. Nature, London, 346, 174-177.
Salzman, C. D., Murasugi, C. M., Britten, K. H., \& Newsome, W. T. (1992). Microstimulation in visual area MT: Effects on direction discrimination performance. Journal of Neuroscience, 12, 2331-2355.

Schmolesky, M. T., Wang, Y., Hanes, D. P., Thompson, K. G., Leutgeb, S., Schall, J. D., \& Leventhal, A. G. (1998). Signal timing across the macaque visual system. Journal of Neurophysiology, 79, 3272-3278.

Sorensen, K. M., \& Rodman, H. R. (1999). A transient geniculoextrastriate pathway in macaques? Implications for 'blindsight'. Neuroreport, 10, 3295-3329.

Standage, G. P., \& Benevento, L. A. (1983). The organization of connections between the pulvinar and visual area MT in the macaque monkey. Brain Research, 262, 288-294.

Stepniewska, I., Qi, H. X., \& Kaas, J. H. (1999). Do superior colliculus projection zones in the inferior pulvinar project to MT in primates? European Journal of Neuroscience, 11, 469-480.

Stewart, L., Battelli, L., Walsh, V., \& Cowey, A. (1999). Motion perception and perceptual learning studies by magnetic stimulation. Electroencephalography and Clinical Neurophysiology, 51(Suppl.), 334-350.

Tanaka, K., \& Saito, H. (1989). Analysis of motion of the visual field by direction, expansion/contraction, and rotation cells clustered in the dorsal part of the medial superior temporal area of the macaque monkey. Journal of Neurophysiology, 62, 626-641.

Tanaka, K., Hikosaka, K., Saito, H., Yukie, M., Fukuda, Y., \& Iwai, E. (1986). Analysis of local and wide-field movements in the superior temporal visual areas of the macaque monkey. Journal of Neuroscience, $6,134-144$.

Tootell, R. B., Reppas, J. B., Kwong, K. K., Malach, R., Born, R. T., Brady, T. J., Rosen, B. R., \& Belliveau, J. W. (1995). Functional analysis of human MT and related visual cortical areas using magnetic resonance imaging. Journal of Neuroscience, 15, 3215-3230.

Ungerleider, L. G., \& Desimone, R. (1986). Cortical connections of visual area MT in the macaque. Journal of Comparative Neurology, 248, 190-222.

Vaina, L. M., Cowey, A., Eskew, R. T., LeMay, M., \& Kemper, T. (2001). Regional cerebral correlates of global motion perception: Evidence from unilateral brain damage. Brain, 124, 310-321.

van Essen, D. C., Newsome, W. T., \& Maunsell, J. H. R. (1984). The visual field representation in striate cortex of the macaque monkey: Asymmetries, anisotropies and individual variability. Vision Research, 24, 429-448.

Watson, J. D. G., Myers, R., Frackowiak, R. S. J., Hajnal, J. V., Woods, R. P., Mazziotta, J. C., Shipp, S., \& Zeki, S. (1993). Area V5 of the human brain: Evidence from a combined study using positron emission tomography and magnetic resonance imaging. Cerebral Cortex, 3, 7994.

Xiao, D. K., Raiguel, S., Marcar, V., \& Orban, G. A. (1998). Influence of stimulus speed upon the antagonistic surrounds of area MT/V5 neurons. Neuroreport, 9, 1321-1326.

Yoshida, K., \& Benevento, L. A. (1981). The projection from the dorsal lateral geniculate nucleus of the thalamus to extrastriate visual association cortex in the macaque monkey. Neuroscience Letters, 22, 103-108.

Zeki, S. M. (1974). Functional organization of a visual area in the posterior bank of the superior temporal sulcus of the rhesus monkey. Journal of Physiology, London, 236, 549-573.

Zeki, S. (1998). Parallel processing, asynchronous perception, and a distributed system of consciousness in vision. The Neuroscientist, 4, 365-372.

Zeki, S., Watson, J. D. G., Lueck, C. J., Friston, K. J., Kennard, C., \& Frackowiak, R. S. J. (1991). A direct demonstration of functional specialization in human visual cortex. Journal of Neuroscience, 11, 641-649.

Zihl, J., von Cramon, D., \& Mai, N. (1983). Selective disturbance of movement vision after bilateral brain damage. Brain, 106, 313-340. 